\title{
Sobre la presencia de éros en Eurípides ${ }^{1}$
}

\section{On the Presence of éros in Euripides}

\author{
Juan Antonio LóPEz FÉREZ \\ https://orcid.org/0000-0002-7684-1880 \\ Universidad Nacional de Educación a Distancia, España \\ jalferez@flog.uned.es
}

RESUMEN: Érōs, érōtos, de la misma raíz que éramai, registrado en griego desde Homero, con escasa presencia en los poemas homéricos, incrementa mucho los usos en los líricos y es bastante utilizado por los trágicos. Eurípides lo recoge en 79 ocasiones: 47, en obras conservadas; más 32 en fragmentos. En este trabajo sólo me ocuparé de los ejemplos donde érōs está relacionado con la pasión amorosa o con el dios Eros, haciendo una selección de los pasajes más relevantes, traducidos al español y acompañados de un comentario centrado en el sustantivo revisado. En nuestra lengua no existe ningún estudio completo dedicado a dicho objetivo, por lo que le podría interesar al lector del trágico, tanto en lo referente a dicho dios como en lo pertinente a la pasión amorosa.

Palabras Clave: Érōs, dios, pasión amorosa, Eurípides

AвSTRACT: Érōs, érōtos, of the same root as éramai, recorded in Greek from Homer, with little presence in the Homeric poems, greatly increases the uses in the lyrical ones and is quite used by the tragic ones. Euripides picks it up on 79 occasions: 47, in preserved works, plus 32 in fragments. In this work I will only deal with the examples where it is related to the passion of love or to the god Eros, making a selection of the most relevant passages, translated into Spanish and accompanied by a commentary centered on the revised noun. In

\footnotetext{
${ }^{1}$ Artículo elaborado dentro del Proyecto FFI2017-82850-R del Ministerio español de Economía, Industria y Competitividad. Mi agradecimiento a los organizadores del III Coloquio Internacional NOVA TELLVS, realizado en la Universidad Nacional Autónoma de México, 2 y 3 de septiembre de 2019, por haberme invitado a presentar la primera versión de este trabajo. Ahora ofrezco el texto ampliado, acompañado de la bibliografía imprescindible. La redacción completa de mi estudio, con el debido aparato bibliográfico, aparecerá próximamente dentro del volumen Eros en la literatura griega, editado por mí mismo, en Madrid, Ediciones Clásicas. Las traducciones son mías. He preferido transcribir el griego a fin de que este escrito sea accesible al mayor número posible de lectores. Quienes deseen leer el texto griego pueden encontrarlo con facilidad en la red.
} 
our language there is no complete study dedicated to this objective, so it could interest the tragic reader, both in relation to said god and in relation to the passion of love.

KeYwords: Érōs, God, Passionate Love, Euripides

RECIBIDO: 01/10/2019 • ACEPTADO: 16/12/2019 • VERSIÓN FINAL: 20/12/2019

Érōs, érōtos, de la misma raíz, desconocida, que éramai, registrado en griego a partir de Homero, con escasa presencia en los poemas homéricos, y sólo en nominativo, aumenta mucho los usos en los líricos y es muy empleado por los trágicos. Eurípides lo recoge en 79 ocasiones: ${ }^{2} 47$, en obras conservadas; más 32 en fragmentos. A esas apariciones hay que añadir 6 de éros, ${ }^{3}$ con ómicron, lo que da un total de 85 secuencias del concepto, presentado con distinto vocalismo.

No me ocuparé en esta ocasión de los ejemplos donde érōs tiene el valor de "deseo", en general, o de carácter especial, pero no relacionado ni con la pasión amorosa ni con el dios Eros. Haré, pues, una selección de los pasajes más relevantes, traducidos al español y acompañados de un comentario centrado en el sustantivo que revisamos.

\section{1. $M E D E A^{4}$}

\subsection{En el prólogo, la nodriza afirma:}

Pues mi señora / Medea no habría navegado hacia las torres de la tierra yolcia, / golpeada en el corazón por amor hacia Jasón (érōti thymòn ekplagê̂s 'Iásonos). ${ }^{5}$

${ }^{2}$ Compárese con la aparición del término en Esquilo (16 veces) y Sófocles (20). El lector sacará provecho de la lectura de los estudios generales sobre Eurípides, señalaré algunos: Conacher 1967, Morwood 2002, Walton 2009, Mastronarde 2010, Lauriola-Demetriou 2015, McClure 2017, etc. Por otro lado, indudable importancia tienen los trabajos que abordan, de algún modo, la presencia del amor en el trágico. Menciono algunos: Adrados 1959 y 1990, Montanari 1973, Bremer 1975, Müller 1980, Sealy 1980, López Férez 1989, Paduano 1992, Luppe 1993b, Zeitlin 1996, Gibert 1999-2000, Márquez Guerrero 2004, Bittrich 2005, Brill 2007, Athanasopoulou 2008, Sanders 2013, Cyrino 2015, Pucci 2016, Sissa 2016, Hualde Pascual 2018, Wickkiser 2018, etc.

${ }^{3}$ Bien conocido desde Homero (20), los otros dos trágicos sólo lo ofrecen una vez cada uno.

${ }^{4}$ Fue representada por primera vez en el 431 a. C.

${ }^{5}$ Med., 6-8. Aparte de la seguida, Diggle 1984, otras ediciones de la pieza, recomendadas y recogidas en la bibliografía son: Elliot 1969, Albini 1990, Mastronarde 2002. Para esta tragedia recomiendo, entre otros, a Gentili 1972 y "Sexual Jealousy and Erôs in Euripides' Medea", en Sanders 2013, pp. 41-58. En general, para los mitos y los personajes míticos en las obras conservadas de Eurípides, con abundante bibliografía, cf. López Férez 2014. 
Señalaré tres elementos: 1. "Golpeada". Que "eros golpea", "aturde" (ekpléssō) es una novedad euripidea; 2. el acusativo de relación ("en cuanto al corazón"), indica la parte corporal afectada por el golpe. Desde Homero el thymós es considerado el asiento de los deseos, a saber, el corazón. 3. El dativo (érōti) funciona como agente de la acción verbal, y rige además un genitivo objetivo (Iásonos), equivalente a un objeto directo: "amor hacia Jasón”, es decir, "amar a Jasón”.

1.2. En el agón retórico Medea-Jasón, éste, en su réplica, afirma entre otros puntos:

Tienes inteligencia fina, mas odioso / argumento resulta explicar que Eros te forzó / con saetas inevitables a salvar mi vida (hōs Érōs s'ēnágkase / tóxois aphýktois toumòn eksôsai démas) ${ }^{6}$

La idea de que Eros obliga (anagkázō) a una persona (Medea) a hacer algo es una expresión innovadora y única en el autor. La construcción metonímica tóxois aphýktois, innovadora también, la encontramos asimismo en Hipp., 1422 (citamos Hipólito por ed. Diggle, 1984).

1.3. El Coro, en la estrofa primera del estásimo segundo, canta así:

Los amores, cuando llegan / en demasía, ni renombre / ni virtud les aportan / a los varones (érōtes hypèr mèn ágan / elthóntes ouk eudoxían / oud'aretàn parédōkan / andrásin). Mas, si con mesura (hális) llega / Cipris, ninguna otra diosa es tan grata. $^{7}$

Me limito a lo esencial: 1. Creo que "los amores" aquí son polisémicos, ya que pudieran referirse a los que diversas personas tienen, pero apuntan, en mi opinión, a los que "una", "cierta persona" (a saber, Jasón) mantuvo por Medea, mirando al pasado, y, en la actualidad, manifiesta por la joven princesa hija de Creonte; 2. la imagen de que esos amores "llegan" a alguien (hyper... elthóntes. Adviértase la tmesis del preverbio hyper-) contribuye a

\footnotetext{
${ }^{6}$ Med., 529-531. Jasón acababa de decir que había sido Cipris, entre los dioses y los hombres, la única salvadora (sôteira) de su viaje por el mar. Ese dardo del antagonista es la contraposición absoluta frente a la afirmación rotunda de Medea respecto a que, según sabían todos los griegos que se habían embarcado junto con Jasón en la Argo, había sido ella quien lo había salvado (v. 476: ésōisá s', hōs ísasin Hellénōn hósoi [...], "Te salvé, como lo saben cuantos helenos [...]". Este pasaje ha sido muy estudiado por los comentaristas por contener una famosa y antológica aliteración de eses, seis veces, además de tres aspiraciones (espíritus ásperos): cf. Page, en su edición de Medea, 1967, pp. 107-108, sobre el sigmatismo del texto y los imitadores y críticos del mismo.
}

${ }^{7}$ Med., 627-631. 
darle cierta apariencia humana a la figura divina. Nótense los recursos morfológicos y sintácticos del trágico para subrayar la idea del exceso: el preverbio hyper- y el adverbio ágan. Esa insistencia contrasta, en seguida, con la posibilidad de que Cipris llegue con mesura (hális); 3. anér, en Medea, equivale a "varón", por oposición a las mujeres (las corintias integrantes del Coro).

1.4. Egeo, rey de Atenas, habla con la heroína, la cual, entre otros detalles, le cuenta la ofensa que le estaba haciendo su esposo (Jasón). Ciñéndonos a la pregunta del ateniense sobre el motivo del deshonor, leemos el siguiente diálogo:

EGEO: ¿Acaso por haberse enamorado (erastheís) o por aversión a tu lecho (è sòn echthaírōn léchos)?

Medea: Al menos con un gran amor. No resultó fiel a sus seres queridos (mégan g'érôta. pistòs ouk éphy phílois) ${ }^{8}$

Egeo deduce rápidamente que la situación podía deberse a dos razones: a que Jasón se había enamorado de otra, o a que odiaba el lecho (es decir, la relación conyugal) de su esposa. A su vez, mégan g'érōta entiéndase como acusativo interno etimológico dependiente de erastheís. ${ }^{9}$

1.5. En el estásimo tercero, el Coro alude a cómo Cipris sopla hacia el Ática las suaves brisas de los vientos:

Llevando siempre / en sus cabellos fragante corona de flores de rosa, / junto a Sabiduría envía a los Amores que se sientan a su lado, (tâi Sophíai parédrous pémpein Érōtas) / de toda virtud colaboradores (pantoías aretâs xynergoús). ${ }^{10}$

Los Amores tienen el asiento junto a la Sabiduría, ${ }^{11}$ cuya actividad comparten en todo. Se trata de una personificación singular de las diferentes manifestaciones del saber: poesía, música, tragedia, historia, etcétera. Eros aparece aquí con un sentido no erótico, pues carece de las notas habituales referentes a la pasión sexual. Obsérvese que los Amores son varios, sin precisar el número.

${ }^{8}$ Med., 697-698.

${ }^{9}$ El TLG recoge varios ejemplos, aparte del aquí presente, de esa construcción etimológica de los dos términos que estamos revisando (éramai-erōs): Ario Dídimo (Liber de philosophorum sectis, 98.1), Plutarco (Dio., 16, 2; Marc., 28, 4; Pel., 4, 4), Opiano (H., 5, 454), Galeno $(2,216,1)$; etc.

${ }^{10}$ Med., 840-845.

${ }^{11}$ Personificada. Cf. López Férez 2002. 
2. HiPólito ${ }^{12}$ (EL TEMA ESENCIAL DE LA PIEZA ES El LLAMADO MOtivo DE Putifar) $)^{13}$

Es la tragedia que contiene mayor número (18) de apariciones del término estudiado, el cual o tiene sentido erótico o se refiere al dios pertinente. Me detendré en esta pieza de manera especial.

2.1. En el prólogo, Afrodita cuenta dónde, por su propia voluntad, surgió la pasión erótica de Fedra hacia Hipólito, su hijastro, hijo de Teseo, su esposo:

Tras verlo, Fedra fue apresada (katéscheto) en su corazón (kardían) / por amor terrible (érōti deinôi), según mis designios (bouleúmasin). ${ }^{14}$

Señalaré cinco puntos: 1. Dentro del prólogo, aparece cuatro veces el término que estudiamos. ${ }^{15}$ No es ningún hecho fortuito, pues resulta ser el concepto esencial en que se apoya toda la trama trágica. Además sirve para explicar la oposición frontal entre esta diosa y Ártemis, la casta, protectora de Hipólito, quien le rinde culto especial. 2. "En su corazón" (kardían) es la traducción de un acusativo de relación: "en cuanto al corazón". Desde los poemas homéricos kardía designa al "corazón", pero también al "asiento de los pensamientos". 3. Deinós (relacionado con deído, "temer") amplía su espectro semántico desde Homero ("terrible", "espantoso") para significar, ya en el siglo v, "poderoso", "extraordinario", "elocuente"; 4. la estrecha asociación de "Cipris" con boúleuma ("designio", "decisión") la vemos asimismo en Sófocles (Fr. 941.17, Radt); 5. el texto trágico no indica expresamente dónde se enamoró Fedra de Hipólito, pero sí señala que fue cuando el héroe había ido a presenciar los misterios y a iniciarse en ellos, lo cual ha de referirse a Eleusis, lugar donde los cultos mistéricos se celebraban cada año.

\footnotetext{
12 Pieza del 428 a. C. Además de la edición seguida, son recomendables las de Ferguson 1994, Halleran 1995, Nenci 2004.

${ }^{13}$ La trama literaria conocida entre algunos estudiosos como "motivo de Putifar" (la mujer casada que se enamora de un joven soltero y que luego, ante las negativas del mismo, lo denuncia por intento de violación) la trató Eurípides en varias tragedias: cf. nuestros apartados 7.7 y 7.8. Dicho tema lo hallamos ya en Homero en el relato épico sobre lo que le ocurrió a Belerofonte por causa de Antea, Il., 6, 154-170. Con referencia a ese motivo literario, presente también en la Biblia, donde precisamente (Ge.39) se habla de las insinuaciones, provocación y acusación falsa realizadas por la mujer de Putifar respecto a José, cf., entre otros, a Yohannan 1968, Kugel 1990, Goldman 2005.

${ }^{14}$ Hipp., 27-28.

${ }^{15}$ Hipp., 28, 32, 39, 41.
} 
2.2. La diosa agrega lo siguiente:

Y antes de volver a esta tierra trocenia, / junto a la misma roca de Palas, ${ }^{16}$ visible / desde esta tierra, un templo de Cipris fundó, / tras concebir, al enamorarse, un amor extranjero (erôs'érōta ékdēmon), y, en lo sucesivo, / (sc. las gentes) nombrarán (onomásousin) a la diosa por haber sido fundado en honor de Hipólito. ${ }^{17}$

Realizaré varias observaciones: 1 . Trocén (o Trecén) era el territorio y la ciudad en la cual había reinado Piteo, abuelo de Teseo y todavía vivo, enfrente de las tierras áticas; el templo fundado por Fedra se alzaba en la Acrópolis ateniense, desde la cual, con tiempo bueno, podía divisarse la costa trocenia, donde entonces estaba viviendo Teseo ${ }^{18}$ con Fedra; 2. en érōta ékdèmon, acusativo interno etimológico, ékdèmon designa a alguien o algo que está en territorio extranjero o ajeno al propio. Parece referirse a Hipólito, el cual, por ser trocenio, se encontraba en territorio ajeno, el de Eleusis, ${ }^{19}$ cuando Fedra lo vio. Puede inferirse que la reina se enamoró de su hijastro cuando ella vivía en Atenas. La tragedia guarda silencio, pero todo apunta a que cuando Teseo tuvo que vivir en Trocén durante un año, precisamente entonces, dentro de ese espacio temporal, la reina había mantenido en silencio el gran amor que había concebido en tiempo pasado, pero que, ahora, se había recrudecido al ver de nuevo a Hipólito, quien vivía con su bisabuelo en el palacio de éste. Y cabe deducir que en la mansión de Piteo, ahora de Teseo, vivían también éste y Fedra durante el año en que el monarca había estado exiliado allí.

2.3-4. La divinidad continúa exponiendo sus razones sobre lo que le estaba ocurriendo a la reina:

Ahora ya, gimiendo y herida / por aguijones del amor (sténousa kakpeplēgménē / kéntrois érōtos), la desdichada fenece / en silencio (sigêi), y ningún servidor

\footnotetext{
${ }^{16}$ Es decir, la Acrópolis.

${ }^{17}$ Hipp., 29-33. Halleran, en su edición de Hippolytos, 1995, p. 149, explica que el trágico está señalando dos hechos muy importantes para la pieza: el amor de Fedra por Hipólito y cómo ella veneraba y daba culto a Afrodita. Con esto pueden entenderse bien las palabras del v. 5, cuando la divinidad sostiene que "a quienes veneran mis poderes les doy preferencia (sébontas tamà presbeúo krátēe".

${ }^{18}$ Cf. Hipp. 34-37, donde la diosa apunta a que Teseo tuvo que marcharse desde Atenas, su verdadera sede, para irse a Trocén, donde estuvo exiliado durante un año, junto con Fedra. Se ausentó de Atenas para huir de la sangre de los Palántidas (los hijos de Palante, hermano de Egeo), pues tuvo que acabar con todos ellos por haberle disputado sus derechos al reino.

${ }^{19}$ No hay acuerdo entre los estudiosos sobre las fechas en que Eleusis pasó a depender de Atenas, porque oscilan al situarlas desde la Edad de Bronce hasta comienzos del s. vi a. C. Haber adjudicado a Teseo la consecución de la unión política entre ambas ciudades pudo ser una noticia propalada en época de los Pisistrátidas, cf. Cosmopoulos 2015, pp. 10-11.
} 
conoce su afección (nóson). ${ }^{20}$ / Mas este amor (tónd'érōta) no ha de caer de ese modo (taútei i...peseîn) / y le mostraré la realidad a Teseo y se verá con claridad. ${ }^{21}$

Haré algunas indicaciones: 1. Nótese la repetición del término érōtos... érōta, el concepto capital para entender la marcha de la obra; 2 . Fedra, mencionada por su propio nombre en el v. 27 , muestra, en palabras de la diosa, algunos indicadores de la pasión erótica; 3. obsérvese "gemir" (sténousa) en la cercanía del sustantivo que revisamos; 4. sobre la relación del verbo "golpear", "aturdir" (ekpléssō) con el amor, ya vista, tenemos ahora una variación sintáctica, pues kéntrois érōtos, un dativo instrumental, funciona como agente del participio pasivo. Es nuestro trágico el primero en recurrir a una metáfora de rara presencia en la literatura posterior. La imagen aparece ya en Esquilo y Simónides, donde se habla del ô̂stros, "aguijón". 5. Innovación euripidea es también la imagen de "morir en silencio". Es importante en el pasaje la afirmación de la propia divinidad en cuanto a que Fedra se estaba muriendo antes de que ésta aparezca en escena, pues es una señal muy relevante para los espectadores sobre la gravedad de la afección que padece la reina. 6. La imagen de la pasión erótica como "enfermedad" (nósos) la hallamos por primera vez en Sófocles (Tr., 489-491, Radt); ${ }^{22}$ 7. la relación de érōs con la noción de "caer" es importante en Eurípides. El trágico es también el primero que vincula a "eros" con la noción de "volar" (potéomai): Hel., 667.

2.5. Dentro del episodio primero, ${ }^{23}$ Fedra dice a las mujeres trocenias del Coro:

Cuando el amor me hirió (m'érōs étrōsen), miraba cómo / lo soportaría del mejor modo. Comencé por esto: / callar y ocultar esta enfermedad (sigân tènde kaì krýptein nóson). ${ }^{24}$

Hay dos elementos esenciales: 1. La imagen de que el amor hiere. Precisamente, el verbo (titrốskō) contiene la idea de "perforar", "herir profundamente", o "de parte a parte". Desde Esquilo contamos con un buen pre-

${ }^{20}$ Es significativa la repetición del vocablo en la tragedia que revisamos. De 50 veces que consta en el autor, 16 están en Hipólito: clara o veladamente referidas a la pasión erótica de la antagonista (vv. 40, 394, 405, 477, 479, 512, 597, 698, 730, 766, 1306), o vinculadas a la desconocida "afección" padecida por ella (vv. 176, 205, 269, 283, 294). Puede afirmarse, pues, sin exageración, que nósos es un hilo conductor, un motivo recurrente, un leitmotiv, de la pieza.

${ }^{21}$ Hipp., 37-41.

${ }^{22}$ La fecha del estreno de las Traquinias sofocleas es muy discutida, pero parece imponerse una datación anterior al 430 a. C.

${ }^{23}$ Muy extenso (vv. 176-524), contiene, como elemento esencial, el diálogo Nodriza-Fedra.

${ }^{24}$ Hipp., 392-394. 
cedente literario, correspondiente a las Danaides (Fr. 44.1-2, Radt). 2. Con respecto a "callar y ocultar esta enfermedad", existen dos curiosos textos tardíos: en el médico Areteo $(C D, 1,1,2)$ y en Luciano (Syr.D., 22).

2.6. Fedra ha manifestado ya su amor, y, además, ha precisado quién es la persona a la que ama: el hijo de la Amazona ${ }^{25}$ cuyo antropónimo verdadero, Hipólito, lo pronuncia la nodriza. Ésta, muy preocupada hasta entonces por el estado físico de su señora, pero conocedora, ahora, de la afección que aqueja a la misma, trata de darle ánimo:

Estás enamorada ( erâis $)$ - ¿qué tiene eso de extraño? - , al mismo tiempo que muchos mortales. / Y, entonces, ¿por un amor (érōtos hoúneka) aniquilarás tu vida? / No les interesa, entonces, ni a los enamorados (tô̂s erôsi) de sus vecinos, / ni a los futuros, si es que resulta preciso que mueran $[\ldots]{ }^{26}$

Es relevante que en tres versos seguidos (439-441) haya sendos vocablos relacionados con el concepto estudiado: verbo-sustantivo-verbo, subrayados en el texto que damos. Es un amontonamiento léxico usado por la nodriza con el fin de convencer a Fedra de que no le está ocurriendo nada raro. Conviene decir que la forma erâis ( $2^{\mathrm{a}}$ p. sg., presente ind. de eráo, "desear vivamente"> "amar"), registrada sólo 12 veces en griego, consta 7 veces en nuestro trágico, y exactamente 2 en Hipólito (también en v. 350), en la única pieza donde tiene que ver con el amor. Que en ambos casos se haga una pregunta (en las dos secuencias formulada por la nodriza) es revelador de la extraordinaria importancia que esa interrogación y la respuesta consiguiente tenían para el público espectador.

2.7. En apoyo de sus argumentos la nodriza recurre al ejemplo de ZeusSémele, la cita alude a Céfalo-Eos y sigue diciendo:

y saben que en otro tiempo arrebató / a Céfalo hasta llegar a los dioses la de hermosa claridad, Eos, / por causa del amor (érōtos hoúneka). ${ }^{27}$

Veamos lo esencial: 1 . Se comenta que $\operatorname{Eos}^{28}$ (la Aurora latina) consigue raptar y llevarse a un mortal hasta el Olimpo, es decir, hasta la presen-

${ }^{25}$ Hipp., 351.

${ }^{26}$ Hipp., 439-442.

${ }^{27}$ Hipp., 454-456.

${ }^{28}$ Era una diosa menor, como sus hermanos Helio y Selene. Hesíodo (Th., 986) indica que Eos unida a Céfalo engendró a Faetonte; por su lado, Apolodoro $(1,9,4)$ señala que Céfalo (hijo de Dión y Diomede) estaba casado con Procris, hija de Erecteo (rey de Atenas), pero, posteriormente, Eos, habiéndose enamorado de él, lo raptó; en cambio, en otro lugar $(3,14,3)$ el mitógrafo lo presenta como hijo de Hermes y Herse: también en este caso Eos se enamoró de él y lo raptó, y, tras unirse con él en Siria, engendró a Titono. 
cia de los dioses (eis theoús); 2. una innovación euripidea es el adjetivo kalliphengés, "de hermosa claridad", utilizado nada más tres veces en el trágico; 3. la expresión preposicional érōtos hoúneka/héneka, con anástrofe, la leemos aquí por primera vez. Sólo la ofrecerá el escolio pertinente.

2.8. Fedra le pide a la nodriza que no siga con sus palabras, hábiles pero infames:

Que tengo bien roturada / el alma por obra del amor (hypeírgasmai... phychèn éróti), y, si mencionas de modo hermoso lo deshonesto, / me consumiré cayendo en lo que ahora rehúyo. ${ }^{29}$

Destacaré dos elementos: 1. La hermosa metáfora agrícola indica los sucesivos ataques del amor, pues apunta al hecho de que la antagonista está bien arada en el alma (acusativo de relación). El amor (dativo instrumental con función de agente de la acción verbal) es propiamente quien ha llevado a cabo toda la labor. El uso de hypergázomai, "preparar para la siembra", "roturar", es otra innovación euripidea; 2. la relación íntima entre "alma""amor" es una innovación sofoclea, seguida de varios ejemplos de nuestro trágico.

2.9. La nodriza vuelve a la carga, conoce medios, no ignominiosos, para que Fedra pueda librarse de su afección:

Tengo en palacio filtros que hechizan / el amor (phíltra moi thelktéria / érōtos), y me han venido hace poco dentro de mi razón, / los cuales, ni con actos deshonrosos ni con daño a tu mente, / harán cesar esta enfermedad (paúsei nósou têsde), si no te vuelves cobarde. ${ }^{30}$

Señalaré los puntos relevantes: 1. La primera correlación entre "filtros""amor" la tenemos aquí; 2. el término phíltron (de la misma raíz que philéo: "instrumento de amor", "medio para conseguir el amor", "bebedizo", "pócima") ${ }^{31}$ conocido por Esquilo, Sófocles y Píndaro goza de notable importancia en Eurípides (16); 3. con respecto al adjetivo thelktếrios, los primeros usos están en Homero, Esquilo y Eurípides. El término, "hechizadores del amor", tiene dos sentidos posibles: ${ }^{32}$ hechizar el esperable amor de Hipólito, para provocarlo, o engañar el real, el que sentía Fedra, para eliminarlo. 4. La imagen de "hacer cesar una enfermedad" está registrada,

\footnotetext{
${ }^{29}$ Hipp., 504-506.

${ }^{30}$ Hipp., 508-512.

31 DEL 2014: Del lat. philtrum, y éste del gr. phíltron, der. de phileîn, 'amar', 'besar'.

${ }^{32}$ Halleran, en su edición de Hippolytos, 1995, p. 193.
} 
como primeros casos, en Sófocles, Heródoto y Eurípides; posteriormente es común, por ejemplo en los tratados médicos hipocráticos.

2.10-13. En el estásimo primero, el Coro, una vez que la nodriza se ha marchado, canta el extraordinario poder de Eros y la destrucción que puede causar:

¡Eros, Eros, que por los ojos / instilas deseo (kat'ommátōn / stázeis póthon), llevando dulce / gozo al alma de los que asedias! / iNunca te me aparezcas con desgracia / ni me vengas sin medida! / Que ni el dardo de fuego ni el de las estrellas es tan intenso / como el de Afrodita que lanza desde sus manos / Eros, el hijo de Zeus (hiésin ek cherôn / Érōs ho Diòs paîs).

En vano, en vano, junto al Alfeo / y en la mansión pítica de Febo, / el sacrificio bovino la tierra Hélade lo aumenta, / mas a Eros, el tirano de los hombres (tòn týrannon andrôn), / el clavero (kleidoûchos) / del gratísimo tálamo de Afrodita, no lo veneramos, I al que destruye a los mortales y les lanza toda desgracia, I cuando llega. ${ }^{33}$

Me ceñiré a lo esencial: 1. La repetición del nombre del dios permite considerar este estásimo como un himno ${ }^{34}$ en honor de Eros; 2. la deidad introduce el deseo (póthon) en los ojos, poniéndolo gota a gota (stázeis) y haciendo que entre en ellos desde arriba hacia abajo (kat'ommátōn). Que el póthos se manifiesta en los ojos ya lo leemos en Esquilo y Sófocles, pero la idea de "instilarlo" allí, "ponerlo gota a gota", es una innovación. 3. El calificativo "sin medida" (árrythmos) es otra novedad léxica; 4. del dardo (bélos) de Afrodita tenemos noticias previas en Píndaro y en la Medea euripidea (Med., 632-634), pero, tanto aquí como en IA, 548-549, es Eros el autor de los disparos: aquí, precisamente, los lanza desde las manos. 5. Eros es presentado en el pasaje como "hijo de Zeus", verdadera innovación en la genealogía de la divinidad: para Hesíodo, había nacido de Caos y Gea; según algún relato órfico, salió del huevo puesto por Noche; Safo lo tenía quizá por hijo de Úrano y Gea, y Semónides, de Afrodita y Ares. La posición del dios al final de la estrofa es relevante. El lector observará que el nombre de Eros aparece como primera palabra en el primero y último verso de la primera estrofa, lugares muy enfáticos. 6. Entiéndase týrannos como "señor absoluto", "dueño", "déspota". El sustantivo es conocido desde el siglo vil a. C. Los trágicos lo usan bastante. Ahora bien, con este calificativo es la primera vez que vemos a Eros en la literatura griega, precisado con el genitivo partitivo andrôn, "de los hombres", es decir, la indicación expresa de los seres

\footnotetext{
${ }^{33}$ Med., 525-543.

${ }^{34}$ Barrett, en su edición de Hippolytos, 1964, p. 257; Furley-Bremer 2001, I, pp. 312-316. Cf. Martínez 1998.
} 
a los que domina; 7. Clavero (kleidoûchos) está acreditado desde Foronis y Esquilo. Eurípides lo ofrece en tres ocasiones. Punto muy relevante es aludir a Eros como el encargado de las llaves del dormitorio, la alcoba, de Afrodita; otra innovación relevante es la alusión a ese lugar tan especial. 8. "No lo veneramos" (sebizomen). La relación estrecha entre Eros y este verbo es única en la literatura griega. Sabemos que existía un culto antiguo en honor de esa divinidad en Tespias (Beocia), y que en el s. v a. C. había un santuario en honor de Afrodita y Eros en la falda norte de la Acrópolis ateniense. ${ }^{35} \mathrm{La}$ consideración expresa de Eros como "dios" (theón) la leemos en griego a partir de Parménides y Sófocles; en tercer lugar, Eurípides. En el s. IV a. C., destaca Platón. 9. "Que destruye a los mortales". Un escolio explica con acierto, a mi entender, "que nos destruye con los amores (tô̂s érōsi)".

2.14. Al final del segundo episodio, Fedra pronuncia las siguientes palabras:

Por amargo amor seré vencida (pikroû érōtos hēssēthésomai). / Mas mal para otro resultaré / tras morir, para que con mis males sepa / no ser ufano (hypsēlòs eînai). Y compartiendo esta enfermedad (nósou) / en común conmigo aprenderá a ser prudente (sōphroneîn) [...]. ${ }^{36}$

Hablaré de varios elementos interesantes: 1. En el s. VII a. C., Safo llama "dulce-amargo" (glykýprikos: Sapph., 130.2, Lobel-Page), al ser no expresado, Eros, el cual es calificado directamente de pikrós, "amargo", a partir de Teognis (Thgn., 1352-1353, Young), y, luego, en nuestro pasaje; 2. la imagen metafórica de "ser vencido/a" por el amor es otra innovación; 3. en el adjetivo hypsēlós cabe destacar aquí el matiz peyorativo de "ufano", "jactancioso", "orgulloso". La soberbia es rasgo definidor de Hipólito, insolencia que a la larga le causará ser aniquilado por obra de Afrodita. El adjetivo hypsēlós es bastante utilizado en Homero y los líricos ("alto", "elevado", "grandioso", "potente", con intención positiva), pero desde Sófocles y a partir de este texto euripideo tenemos un valor negativo respecto al comportamiento: "orgulloso", "prepotente"; 4. con la expresión "compartiendo esta enfermedad" entiéndanse los efectos nocivos, patológicos, generados por la pasión erótica; en ella, por exceso, y en él, por defecto, por su castidad mantenida a toda costa; 5 . el verbo sōphronéo (lo mismo le ocurre al adjetivo correspondiente, sóphrōn, y al sustantivo sōphrosýne) adquiere un matiz especial en esta tragedia, pues si el significado general es "ser prudente", "ser moderado", aquí tiene el sentido de "ser casto", mantener la pureza en el terreno sexual. ${ }^{37}$

\footnotetext{
35 Barrett, en su edición de Hippolytos, 1964, p. 261.

${ }^{36}$ Hipp., 727-730.

${ }^{37}$ Cf. López Férez 1987.
} 
2.15-16. Tras la salida de Fedra, el Coro, en la antístrofa del estásimo segundo, canta cómo su señora concibió, por obra de Afrodita, el amor que la llevaría a la muerte, a saber, ahorcándose en la alcoba matrimonial:

Por ello, con terrible enfermedad (deinâi... nósōi) / de amores no santos obra de Afrodita (ouch hosión erótōn... Aphrodítas), / (sc. mi señora) vio roto su corazón (phrénas... kateklásthē). I [...] Prefiriendo ilustre fama (eúdoxon... phéman) I y apartando del corazón (apal- / lássousá t'... phrenôn) su doloroso amor (algeinòn...érōta). ${ }^{38}$

He aquí los elementos más conspicuos: 1. "Terrible enfermedad" se halla, por primera vez, en Sófocles, referido a Heracles (Tr., 980-981); después en el pasaje que estamos viendo; 2. "de amores impíos" (literalmente, "no santos") es un genitivo apositivo o explicativo dependiente de "enfermedad", es decir, equivalente a "enfermedad que consiste en amores impíos". El adjetivo hósios alude a lo que les está permitido, o recomendado, a los hombres por los dioses: "santo", "piadoso", "lícito". 3. A su vez, traduje como "obra de Afrodita" el simple genitivo Aphrodítas, pues funciona, a mi entender, como genitivo de autor, el que indica quién realiza la acción apuntada en el concepto regido: "amores causados por Afrodita". Eurípides es el primero en recurrir a esa distribución sintáctica, bastante rara; 4. "romperse el corazón”. El giro sintáctico (con el verbo katakláo y acusativo de relación phrénas) es tan raro que constituye un verdadero hápax en griego. Por su lado phrên (plural phrénes), muy usado desde Homero, poco en los líricos, es bien conocido por los trágicos y preferido en lugar de kardía. Para el hombre homérico las phrénes equivalen al "corazón", pero también al "lugar de los pensamientos". 5. La "ilustre fama". La phếmè es desde los poemas homéricos "lo que dicen", "lo que se cuenta". De ahí pasó a referirse a lo que se afirma sobre una persona concreta, a saber, su "fama". En el texto examinado dicho sustantivo aparece con eúdoxon, "de buena opinión", "famosa", "ilustre". La pareja constituye otro hápax léxico en griego; 6. "apartar de su corazón": el genitivo de plural phrenôn apunta a la separación o alejamiento propio de la noción verbal (apallássousa). Por otro lado, que eros se asienta en las phrénes es una idea que está ya en Homero y Píndaro. 7. "Doloroso amor" constituye otro par léxico innovador, que sólo siglos más tarde volverá a ser registrado.

2.17. El estásimo cuarto es un himno en honor de Afrodita, y en él Eros ocupa un lugar muy relevante:

Tú el inflexible corazón (ákampton phréna) de dioses y mortales conduces (ágeis), / Cipris, atacándolo (amphibalòn) al mismo tiempo / en derredor el ala-

${ }^{38}$ Hipp., 763-766, 773-775. 
do variopinto (ho poikilópteros) / con velocísimas alas (ōkytátōi pterôi). / Vuela (potâtai) por la tierra y hacia el resonante / mar salado, / y encanta (thélgei) Eros a quien en su delirante corazón (mainoménai kradíai) / asalta (ephormásēi) alado de áureos reflejos (ptanòs xrysophaês): / la naturaleza de retoños montaraces y marinos, / y a cuantos la tierra nutre / y a los que el llameante sol contempla, / y también a los hombres (ándras). Sobre todos éstos poder soberano, / Cipris, tú sola posees. ${ }^{39}$

De mi interés son: 1. En los primeros tres versos, la imagen de la caza: la diosa impulsa, arrea (ágeis. Uno de los sentidos de ágō es arrear animales que van caminando por delante de quien los dirige a alguna parte). Nótese la referencia al corazón (aquí phréna) que no cede (ákampton, propiamente, "que no se dobla", o "doblega"), es decir, el de los dioses y hombres que no se rinden ante las exigencias de la diosa del amor. La expresión es única en la literatura griega; 2. mientras Cipris conduce esos corazones, Eros los está asediando con sus vuelos rapidísimos. En el participio amphibalón ${ }^{40}$ está el sentido de echar la red en torno a algo o alguien. Por otro lado, en sólo seis versos (1270-1275) se insiste cuatro veces en la condición de alado, dotado de alas, propia de Eros (poikilópteros-pterôipotâtai-ptanós). El primer adjetivo, nada más registrado en tres ocasiones dentro de la literatura griega, es aquí innovador al atribuirse al dios, a saber, que tiene alas de varios colores; 3. advertimos que el movimiento de Eros por el aire se dirige hacia tierra, dos de los elementos esenciales entre los Presocráticos; 4. aunque pterón, "ala", es bien conocido desde Homero, la pareja léxica en que aparece junto a "rápida" es innovadora; 5. la relación léxica Eros-"encantar" (thélgō) aparece en primer lugar en Sófocles (Tr., 354-355), y, luego, en este texto euripideo; 6. el dios encanta al animal o a la persona a la que haya asaltado en su corazón enloquecido (mainoménai kradíai); 7. hay aquí dos elementos dignos de subrayar. En primer lugar, la divinidad "encanta", "engaña". Desde Homero, el verbo thélgo tiene esos valores: en Hom., Od., 12, 40 y 44, se dice de las Sirenas que seducían con sus cantos a los que navegaban cerca de ellas, y que, si aproximaban su navío, se condenaban a una muerte segura. En segundo lugar es cierto que el dios asalta, pero a quien tiene su corazón enloquecido, es decir, poseído o dominado por la manía, la locura. 8. Es única en griego la pareja ptanòs xrysophaếs. El adjetivo ptanós, "alado", "dotado de alas", aquí sustantivado, lo presentan, primero, los tres trágicos. El nuestro, con veinte ejemplos, tiene cierta predilección por este adjeti-

\footnotetext{
${ }^{39}$ Hipp., 1268-1281.

${ }^{40}$ Halleran, en su edición de Hippolytos, 1995, p. 256, señala que en el pasaje aparecen tres verbos (ágō, amphibállō y ephormáó) relacionados con la caza, imagen que evoca el terreno marcial, metáfora asociada a la pareja Eros-Afrodita.
} 
vo. En cuanto a xrysophaếs, "de áurea luz", "resplandor", Eurípides es el segundo autor en utilizarlo, pues en fecha anterior solamente lo leemos en un fragmento lesbio de autor incierto; 9. el lector reparará en los objetos directos abarcados por el asalto de Eros: todos los animales de montaña y los marinos, y todos cuantos alimenta la tierra y a los que contempla el sol, y a los hombres. En otras palabras, se alude a todos los seres animados. Los hombres (ándras en el texto; con valor general: "los seres humanos"), aquí los últimos, ocupan lugar enfático. Es mención única también la pareja ephormáō-phýsis. Véase la construcción de phýsin más genitivo (phýsin... skýmnōn), donde éste podría entenderse como explicativo o epexegético: "naturaleza que consiste en los retoños...". 10. Quien lea el himno a Eros presentado por Sófocles en Antígona (781-800) observará algunas coincidencias en varios motivos: el dios va y viene sobre el mar y por agrestes moradas; no se le escapa ningún dios ni hombre; el que lo tiene, enloquece.

2.18. En el episodio quinto, Ártemis, la divinidad protectora de Hipólito, afirma lo siguiente:

Y, no, por caer carente de nombre, / Eros, el de Fedra hacia ti, quedará en silencio (kouk anónymos pesòn / érōs ho Phaídras eís se sigēthésetai). ${ }^{41}$

Haré algunas observaciones: 1. Es una innovación lo de caer sin nombre (anốnymos), es decir, de modo anónimo; 2. La imagen de Eros que cae en algún sitio o sobre alguien la hallamos ya en Sófocles (Ant., 782); 3. "Eros, el de Fedra", es una libertad sintáctica en virtud de la cual el poeta retrasa el artículo determinador de algún sustantivo relevante y lo pone a continuación con un genitivo íntimamente ligado al sustantivo anterior; 4. Halleran, en Hippolytos, 1995, p. 266, observa que el adjetivo anónymos corresponde al término avanzado en el v. 1 por la propia Afrodita, cuando habla de sí misma como divinidad importante y no "carente de nombre", y de inmediato afirma que se llama Cipris. Nótese que el mismo concepto se dice allí de la diosa y ahora aquí de Eros. El léxico, pues, une también inextricablemente a ambas divinidades. 5. Considérese Phaídras como genitivo subjetivo, equivalente a "Eros, el que experimenta Fedra"; 6. repárese en la construcción preposicional eís se, "hacia ti", acusativo de dirección. Es otra innovación sintáctica euripidea.

${ }^{41}$ Hipp., 1429-1430. 


\section{TROYANAS ${ }^{42}$}

3.1. En el episodio primero, dialogan Taltibio, heraldo de los aqueos, y Hécuba. Ésta pregunta sobre el destino que le había sido impuesto a Casandra; aquél, que había afirmado que Agamenón se la había reservado para él, contesta:

Eros por la joven de furor divino lo asaeteó (érōs etóxeus'autòn enthéou kórēs) ${ }^{43}$

Hay varios elementos relevantes: 1. La pareja érōs-toxeúō (este verbo significa "disparar el arco") es una innovación literaria, recogida en la literatura posterior; 2. entiéndase el genitivo enthéou kórēs como objetivo, dependiente del sustantivo estudiado y equivalente en el plano funcional a un complemento directo. La pareja léxica éntheos kórē es una primicia euripidea; tanto aquí como en $E l ., 1032$, apunta a Casandra, por su relación estrecha con Apolo.

3.2-3. En el estásimo segundo, el Coro se ocupa del tema troyano, y, dentro del mismo, se detiene, de modo velado, en la relación de Eros con el Juicio de Paris:

¡Eros, Eros, que a los palacios dardáneos ${ }^{44}$ viniste un día, / atendiendo a las uránidas. ${ }^{45}$ / ¡Cómo en otro tiempo ensalzaste en alto modo a Troya, / al establecer lazo familiar ${ }^{46}$ con dioses. . $^{47}$

Es una novedad literaria adjudicar a Eros la intervención en el Juicio de Paris, así como haber facilitado la unión de dos dioses con dos troyanos

42 Pieza del 415 a. C. Además de la edición seguida, recomendamos las de Taccone 1942, Hargreaves 1976, Barlow 1986.

${ }^{43} \operatorname{Tr} ., 255$.

${ }^{44}$ Aquí equivale a "troyanos". Dárdano, hijo de Zeus y de la Atlántide Electra, fue el antepasado remoto de la casa real troyana. Entre los trágicos sólo lo nombran Sófocles (1) y Eurípides (4, más 8 formas adjetivales).

${ }^{45}$ Referencia a las tres diosas: Afrodita, Hera y Atenea que tomaron parte en el famoso Juicio de Paris. Estaban ligadas en diverso grado con Úrano, pues eran, respectivamente, hija, nieta y bisnieta del citado. El patronímico "uránida" lo vemos por primera vez en Hesíodo (2), y, después, en Píndaro (3) y Eurípides (7), el único trágico que lo utiliza.

${ }^{46}$ Alusión a dos relaciones familiares surgidas tras sendos raptos: el de Ganimedes realizado por Zeus (a aquél se le menciona unos versos antes como "niño laomedontio", con la precisión de que llena las copas del soberano olímpico. Realmente Ganimedes era hijo de Tros, que fue padre también de Ilo, de quien nació Laomedonte, padre, a su vez, de Príamo. El trágico, el único que menciona a Ganimedes, en 4 ocasiones, es prudente en los vv. 845-846, cuando el Coro afirma: "Y el oprobio de Zeus / no lo diré") y el de Titono (hijo de Laomedonte), por obra de Eos.

${ }^{47} \operatorname{Tr} ., 840-845$. 
ilustres (a saber, Zeus con Ganimedes; Eos, con Titono). El Coro lo expresa de forma casi enigmática, difícil de entender. ${ }^{48}$

\section{HELENA 49}

En el episodio segundo, dentro de un diálogo entre Helena y Menelao, la primera, como éste le pidiera que le contara desgracias pasadas, habla con él en versos líricos:

HeLENA: Sin que hacia el lecho de un joven bárbaro / volara el remo (petoménas kópas) ni volara / el deseo de boda ilícita (petoménou d'érō- / tos adíkōn gámōn) [...]

MeNelao: ¿Qué divinidad o destino te arrebata de tu patria?

Helena: [...] el nacido de Zeus, el hijo de Zeus, joh esposo!, <y de Maya> / me condujo dejándome en el Nilo. ${ }^{50}$

Hay dos metáforas seguidas: una el vuelo del remo y otra el vuelo del deseo erótico, acompañadas de la repetición del participio peto-... peto-. A su vez, esa iteración fónica subraya la rapidez de los remos y la ligereza del deseo. Cabe aceptar que érōtos sea simplemente el "deseo", mas existen dos elementos que nos inclinan a pensar en el sentido erótico que analizamos: 1. Llevar el genitivo objetivo "bodas ilícitas" (gámos es un término polisémico que significa tanto "boda" como "unión sexual"). La referencia a "ilícitas", "ilegales", debe entenderse en la idea de que se alude a una mujer casada y con una hija, pero que (según varios relatos míticos) se había marchado a vivir con un joven soltero (Paris). Por lo demás, la concordancia ádikos-gámos es una innovación euripidea. 2. "Volar" es una capacidad

48 Barlow 1986, p. 203, comenta que en los versos anteriores (Tr., 820-839) el Coro de cautivas troyanas critica que Ganimedes esté llenando las copas de Zeus y permanezca junto al trono del dios supremo mientras Troya ha sido destruida por las lanzas griegas. Asimismo en versos siguientes al texto que ofrecemos ( $T r$., 845-859), el Coro menciona a Zeus, a quien no se atreve a censurar, y a Eos, a la que sí le echa en cara que haya contemplado la aniquilación de la ciudad mientras comparte su lecho con su esposo (sc. Titono, no mencionado expresamente) y padre de sus hijos, quien fuera arrebatado por la cuadriga áurea de los astros. Efectivamente, Apolodoro $(3,12,4)$ explica que Eos raptó a Titono por causa del amor y se lo llevó a Etiopía, donde se unió con él y tuvo a Ematión y Memnón.

49 Tragedia del 412 a. C. Además de la edición seguida, son recomendables las de Dale 1967, Kannicht 1968, Allan 2008.

${ }^{50} \mathrm{Hel}$., 666-671. El hijo de Zeus y Maya es Hermes, no citado expresamente en el pasaje, pero sí los nombres de sus progenitores. Precisamente, en Hel., 241-248, la protagonista expone en versos líricos que Hermes, enviado por Hera, la había arrebatado mientras cogía flores y se la llevó por el éter hasta Egipto. 
propia de Eros, y, aunque se podría también aplicar al deseo, la asociación del dios con esa virtud de marchar por los aires sería fácil de captar para el espectador medio.

\section{IFIGENIA EN ÁULIDE ${ }^{51}$}

5.1. El Coro elogia la moderación en el amor, para censurar en el epodo, el conflicto generado por el comportamiento de Paris y Helena:

Felices los que, siendo la divinidad mesurada (metrías theoû), / con castidad (sōphrosýnas) participan / de las uniones de Afrodita, / gozando con calma de sus enloquecidos aguijones, cuando ya / Eros de áurea cabellera (chrysokómas Érōs) tiende / sus arcos dobles de gracias (dídym'... tox' enteínetai charítōn): / uno, con destino feliz, / el otro, con perturbación de la vida. / Rechazo éste de mi / tálamo, oh Cipris bellísima, y sea moderado (metría) / mi deleite y santos mis deseos y / participe de Afrodita, / mas rechace a la excesiva (pollán). ${ }^{52}$

Veamos: 1. La presencia de Eros de áurea cabellera (chrysokómas) está ya en Anacreonte ( $F r .13 .2$, Page). El calificativo lo utiliza otra vez nuestro trágico para referirse a Apolo (Tr., 254). Dicho adjetivo lo hallamos aplicado a otras divinidades desde Hesíodo, Alcmán, Píndaro, etcétera; 2. es la primera ocasión en que tenemos el triple juego léxico Érōs-enteínotóxon. Esquilo ( $F r .83 .4$, Radt) es el primero en relacionar estrechamente enteínō-tóxon y, luego, viene nuestro trágico. 3. La relación dídymontóxon, "doble"-"arco", innovación de Eurípides, el único que la registra, la citará dos veces Ateneo $(13,562 \mathrm{e}$; además, en la Epit., 2, 2, 104, 16); 4. respecto al genitivo charítōn, dependiente de tóxa, cabe traducirlo como explicativo o epexegético: "arcos que son gracias". Sólo aquí contamos con esa relación sintáctica y léxica. 5. Fuera de lo concerniente a eros, conviene reparar en la insistencia de la "moderación", "mesura", tanto de Afrodita como del deseo (sc. sexual), manifestada por el Coro (metría... metría), así como la invocación de éste para que la diosa no sea excesiva (pollá, con vocalismo dórico).

5.2-3. En ese mismo estásimo, dentro del epodo, el Coro alude a Paris, el juicio y su encuentro con Helena en la Hélade: ${ }^{53}$

\footnotetext{
51 Obra del 405 a. C. Fuera de la edición seguida, es recomendable la de Firnhaber 1841; además, las de Jouan 1983, y Calderón 2002.

${ }^{52}$ IA, 543-557.

${ }^{53}$ Dicho texto ofrece serias dificultades en la transmisión y es muy discutido por los estudiosos.
} 
Vacas de buenas ubres se nutrían, / y a ti te enloqueción ${ }^{54}$ el juicio de las diosas, / que te envía a la Hélade. I Ante el trono ${ }^{55}$ / de adornos marfileños, deteniéndote, / en los ojos de Helena que de frente te miraban (Helénas / en antōpoîs blephárois) / amor diste (érōta t'édōkas) y por amor / tú mismo fuiste perturbado (érōtí t' I autòs eptoéthēs $).{ }^{56}$

Me limito a lo relativo al Amor: 1. En la frase "en los ojos de Helena que de frente te miraban", el adjetivo antōpós, primicia euripidea, equivale etimológicamente a "que está enfrente del ojo". Más relevante es la precisión de que Paris da amor "en los ojos", es decir, dejándolo caer en los ojos de Helena. 2. "Amor diste" es otra imagen innovadora; 3. la combinación léxica “amor"-ptoéō/ptoiéo (aquí, en pasiva, "ser perturbado", "ser agitado", "ser conmocionado") es otra innovación euripidea.

\section{BACANTES 57}

En el estásimo primero el Coro manifiesta sus deseos de escapar a tierras donde el culto dionisiaco no estuviera reprimido. En cuatro versos se expresa del siguiente modo:

¡Ojalá llegara a Chipre, / isla de Afrodita, / donde hechizadores del corazón / de los mortales habitan los Amores (hoi thelxíphrones némon- / tai thanatô̂si Érōtes)! [... $]^{58}$

Veamos dos puntos: 1. El adjetivo thelxíphrones sólo aquí califica a los Amores. El término, no comentado por ningún léxico griego antiguo, es un compuesto de rección en que el primer elemento rige al segundo: equivale a "que encantan los corazones"; 2. algunos explican que thanatoîsi va ligado a thelxiphrones. Puede tratarse de un dativo propio que señalaría a las personas que poseen esos corazones, es decir, los mortales ("corazones de los

\footnotetext{
${ }^{54}$ Diggle 1994 lee émene $\dagger$, imperfecto de ménō, “esperaba”, pero señalado con una cruz, indicador de texto dañado. En cambio, émēne, aoristo de maínō, "enloqueció", conjetura de Hermann (1846-1847), es aceptada por numerosos editores: Murray 1909; Jouan, en su edición de Iphigénie à Aulis, 1983; Calderón, en Ifigenia en Áulide, 2002. Me he inclinado por esta lectura.

${ }^{55}$ La lectura thrónōn es una conjetura de Hermann 1846-1847, aceptada por bastantes editores. Los manuscritos leen dómōn, "casa", "mansión", "palacio". Parece tener más sentido que Paris se detenga de pie ante el trono donde está sentada Helena, y no delante del palacio. Por otro lado las incrustaciones de marfil son más propias de un trono que del exterior del palacio.

${ }^{56}$ IA, 579-586.

57 Tragedia del 405 a. C. Además de la edición seguida, son relevantes las de Dodds 1970 y Seaford 2001.

${ }^{58}$ Ba., $402-405$.
} 
mortales"), pero también cabría entenderlo como dativo de interés: "corazones en provecho de los mortales".

\section{FRAGMENTOS}

Los fragmentos proporcionan 32 ejemplos. La disposición aquí será alfabética, tal como la ofrecen Kannicht 2004 y Jouan-van Looy (en cuatro volúmenes: 1998, 2000, 2002 y 2003), ciñéndome a los aspectos esenciales para nuestro objetivo. ${ }^{59}$

\subsection{Andrómeda ${ }^{60}$}

7.1.1. Perseo, antes de marcharse a combatir contra el monstruo marino que amenazaba con devorar a la encadenada Andrómeda, suplica a Eros que le ayude en su empresa:

Y tú, oh tirano de dioses y de hombres (týranne theôn te kanthrốponn), Eros, / o no enseñes (mè dídaske) a que los seres hermosos se muestren hermosos, / o a los amantes (toîs erôsin) de que tú eres artesano (dèmiourgós), / mientras sufren sus sufrimientos, ayúdales con buena fortuna, / y haciendo eso serás venerado (tímios) entre los mortales, / mas, de no hacerlo, por la misma acción de enseñarles a amar (toû didáskesthai phileîn) / serás privado de las gracias (cháritas) con que te honran (timôsí se). ${ }^{61}$

Hay varios elementos relevantes: 1. Ya hemos visto la imagen de Eros como tirano de los hombres, pero aquí el dominio absoluto de la divinidad abarca también a los dioses; 2. "no enseñes". En la pareja léxica "amor""enseñar" (didáskein), es la primera vez que eros es sujeto de la educación impartida. La imagen de amor "enseñando" tuvo éxito posteriormente en poetas y prosistas. Por su lado, la concepción de Eros como dēmiourgós,

\footnotetext{
${ }^{59}$ Indico tanto el número del fragmento como los versos en que aparece el término estudiado. Por razones de espacio, no profundizo ni en los temas míticos desarrollados en esas obras ni en numerosos detalles respecto a los héroes y personajes allí citados. Como estudio general, acerca de la recepción de los fragmentos euripideos, cf. Martínez Bermejo 2017. Por su posible interés, recogeré las aportaciones relevantes dedicadas a cada obra fragmentaria de que nos ocupemos.

60 Obra estrenada en el 412 a. C., junto con la conservada Helena. Jouan-van Looy 1998 recogen 42 fragmentos auténticos, más 10 dudosos o espurios. Para la reconstrucción de la pieza son imprescindibles Aristófanes, los Catasterismos del Pseudo-Eratóstenes, Apolodoro, Diógenes Laercio, Estobeo, Higino y el POxy. 2628 de los ss. I-II d. C. Entre la abundante bibliografía dedicada a la obra destacan: Müller 1907, Webster 1965, Rau 1967, Philips 1968, Moorton 1987, Mureddu 1987, Tessier 1973-1974.

${ }^{61} \mathrm{Fr} .136 .1$ (= 21 Jouan-van Looy, 1998). El texto fue transmitido por Ateneo $(13,561 \mathrm{~b})$ y Estobeo $(4,20 \mathrm{~b}, 42)$.
} 
"artesano", aparece aquí primero. 3. Tímios, adjetivo conocido desde Homero, Hesíodo, los líricos, etcétera, alude a la persona que ha recibido su honra, la timé, a saber, el aprecio que merece a ojos de los demás. Es innovadora la aparición junto a Eros; 4. otra idea novedosa es la de enseñar a amar (philéo entra aquí en el terreno de la pasión erótica).

7.1.2. Sobre el fragmento siguiente no hay seguridad ni acerca de si es auténtico o espurio, ni respecto a su distribución dentro de la pieza:

Tenemos amor peligroso (érōta deinón), y de mis argumentos / selecciona lo mejor. Que asunto infiel (hōs ápiston est'erōs) es amor / y en el lugar peor de nuestro corazón (phrenôn) suele habitar (oikeîn philể). ${ }^{62}$

Haré algunas observaciones: 1. A pesar de nuestra traducción, el término deinón puede estar sustantivado: "amor como algo peligroso"; 2. algo después, no cabe duda de que ápiston está sustantivado y de que funciona como predicativo de nuestro sustantivo; 3 . sobre las phrénes ya hemos tratado; 4. otra innovación euripidea es ocuparse del lugar donde eros suele habitar (es decir, tener su domicilio habitual, su oîkos). Vemos algún reflejo en Platón (R., 573d: a tenor de este pasaje, Eros habitaría en las fiestas, gozos, cortesanas y otros asuntos de ese jaez).

\subsection{Antígona ${ }^{63}$}

7.2.1. En el agón entre Creonte y Hemón, su hijo, éste pronunciaría las siguientes palabras:

Yo amaba (érōn). El enloquecer (tò maínesthai) era, pues, amor para los mortales (érōs brotô̂s). ${ }^{64}$

Señalaré varios detalles: 1. La presencia del verbo eráōoráomai, "amar", "enamorarse", se localiza en un contexto próximo a nuestro sustantivo. Di-

${ }^{62}$ Fr. 138a.1.2 (= 3 Jouan-van Looy, 1998, entre los dudosos). El fragmento fue recogido por Estobeo (4, 20a, 44). Tiene el número 1054 en Nauck 1889.

63 Presentada quizá entre 415-409 a. C., es posterior a la pieza conservada de Sófocles. Jouan-van Looy 1998, p. 200, recogen 24 fragmentos e indican en su edición que temas principales de la obra son el amor y el matrimonio. Para la reconstitución de la misma son necesarios los testimonios de Aristófanes el comediógrafo, Aristófanes de Bizancio, y, asimismo, Estobeo y el POxy. 3214 del s. II. Con todo, subsisten muchas dudas. Numerosos estudios le han dedicado a esta tragedia, cito algunos: Huddilston 1899, Paton 1901, Mesk 1931, Lucas 1937, Xanthakis-Karamanos 1987, Luppe 1989, Scodel 1982, Kannicht 1992, Ghiron-Bistagne 1993.

${ }^{64} \mathrm{Fr} .161$ (= 10 Jouan-van Looy, 1998). Recogido por Estobeo $(4,20 \mathrm{~b}, 38)$ y Plutarco $(F r$. 136.40, Sandbach). 
cho verbo, conocido desde Hesíodo y los líricos, es frecuente en los trágicos y Heródoto; 2. la relación entre el verbo maínō, "enloquecer", y érōs es una innovación euripidea; 3. la interdependencia entre érōs y brotós, "mortal”, y, por extensión, "hombre", "ser humano", aparece ya en Esquilo (Ch., 598 y 602), pero es dilecta de Eurípides.

7.2.2. Dentro del agón ya referido, Creonte se queja ante Hemón de lo difícil que es vigilar a los hijos:

Cuando un joven mira hacia Cipris, / sin guarda resulta la vigilancia. Que aun siendo vulgar (phaûlos) / en lo demás, para el amor todo varón es bastante sabio (eis érōta... sophôteros), / y, si le asiste Cipris, gratísimo es iniciarlo. ${ }^{65}$

Sólo me centraré en lo referente a Eros: 1. El adjetivo phâ̂los, propio de la lengua familiar, no raro en buen sentido ("sencillo", "sin afectación", hablando de personas), es más común con el matiz negativo ("inhábil", "ineficaz", "vulgar", "iletrado"); 2. la oposición de dicho término respecto a sophós está ya en Sófocles (Fr.771.1-2, Radt), pero es nuestro autor el que la usa con frecuencia; 3 . muy relevante es el adjetivo sophós, ausente de la épica y con escasas apariciones en los líricos. De entre los trágicos sobresale Eurípides (244).

\subsection{Auge 66}

Heracles, el gran héroe panhelénico, intenta excusarse sobre el acto otrora cometido (haber violado tiempo atrás a la protagonista), aludiendo a la fuerza irresistible del amor:

Quienquiera que no juzgue a Eros dios grande (theòn mégan) / y el más poderoso de todas las divinidades (tôn hapántōn daimónōn hypértaton), / por ser torpe o inexperto en lo hermoso / no conoce al dios más importante para los hombres (ouk ô̂de tòn mégiston anthrốpois theón) ${ }^{67}$

\footnotetext{
${ }^{65} \mathrm{Fr} .162 .3$ (= 13 Jouan-van Looy, 1998). El último verso ofrece algunos problemas textuales. El fragmento fue transmitido por Estobeo $(4,20 a, 4)$.

${ }^{66}$ Asunto debatido es la fecha de su estreno, quizá fue entre 414-406 a. C. por motivos métricos. Jouan-van Looy 1998 aceptan 24 fragmentos. La reconstitución de la obra resulta muy complicada dadas las versiones divergentes de los mitógrafos y el gran número de tragedias inspiradas en el tema de Auge-Heracles-los Aléadas. Cito algunas contribuciones dedicadas a la obra perdida: Brizi 1927; Zielinski 1927; Koenen 1969; Kannicht 1976; Anderson 1982; Luppe 1981, 1983 y 1986; Huys 1989-1990; Brulé 1996.

${ }^{67}$ Fr. 269.1 (= 13 Jouan-van Looy, 1998). El texto fue recogido por Estobeo $(4,20 a, 11)$ y, parcialmente, por Ateneo $(13,600 \mathrm{~cd})$.
} 
Destacaré dos cosas: 1. Calificar a Eros de "dios grande" lo leemos aquí como primicia; 2 . tener a esa divinidad como la más poderosa, juicio también innovador, lo encontraremos hasta autores tardíos.

\subsection{Dánae ${ }^{68}$}

Se habla del amor como privilegio de las personas ricas y ociosas, mientras que los pobres tienen que pensar en su sustento:

Eros es de nacimiento algo ocioso (argón) y dado a asuntos tales. / Ama espejos y teñidos rubios de la cabellera (philê̂ kátoptra kaì kómēs xanthísmata), / rehúye esfuerzos (móchthous). Una sola prueba tengo: / ningún mortal que mendigue su alimento (prosaitôn bioton) se enamoró (érásthē), / mas, entre los que tienen ${ }^{69}$ aquél ${ }^{70}$ es juvenil (hēbētếs) de nacimiento. ${ }^{71}$

Veamos ahora algunos puntos: 1. La relación entre Eros y la condición de "ocioso" es una innovación euripidea; 2. es relevante que kátoptron ("espejo", 4 apariciones en este trágico) ${ }^{72}$ aluda en las otras tres ocasiones a mujeres que se peinan ante el espejo o que se miran en él; 3. a propósito de xánthisma, "teñido de rubio", innovación euripidea, es importante un pasaje de Clemente de Alejandría (Paed., 3, 3, 16, 2), quien critica que ciertos hombres usen teñidos para el pelo, ungüentos para las canas y tintes especiales de rubio para sus peinados; 4. la idea de que Eros huye de los esfuerzos es innovadora; 5. la construcción "mendigar el alimento", novedosa, la tenemos sólo otras dos veces en griego posterior; 6. el término hēbētés, aquí adjetivo, apunta a lo que es juvenil, en la plenitud de las fuerzas, a lo situado cronológicamente entre el final de la adolescencia y la edad adulta.

\subsection{Dictis $^{73}$}

\footnotetext{
${ }^{68}$ Respecto a su estreno, se han propuesto, por razones métricas, fechas entre 455 y 425 a. C. Jouan-van Looy 2000 presentan 17 fragmentos. Para su reconstitución son imprescindibles Estobeo y Juan Malalas. Entre las aportaciones consagradas a esta pieza recojo algunas: Wünsch 1896, Rein 1926, Radermacher 1927, Morelli 1974, Luppe 1991 y 1993a, Kannicht 1992.

${ }^{69}$ El verbo aparece con valor absoluto, sin complemento alguno: piénsese en un objeto directo como "riquezas", "medios de vida".

${ }^{70}$ Entiéndase, Eros. Cf. Assaël 1992.

${ }^{71}$ Fr. 322.1 (= 17 Jouan-van Looy, 2000). Estobeo (4, 20b, 40) nos ha legado el fragmento, aludido también, parcialmente, por Plutarco (760d).

${ }^{72}$ Los únicos precedentes son Esquilo (3) y Ferecides de Siros (1).

${ }^{73}$ Formó parte de la tetralogía presentada en el 431 a. C. (Medea, Filoctetes, Dictis y el drama satírico los Recolectores). Jouan-van Looy presentan 19 fragmentos. Para la reconstitución de la obra es imprescindible el testimonio de Estobeo, quien ha transmitido 15 de los 19 textos que nos han llegado. Entre las aportaciones en que se estudia esta tragedia perdida señalo la de Körte 1932.
} 
7.5.1. Un personaje desconocido (quizá Dánae le habla a Dictis) ${ }^{74}$ dice así:

Que era querido para mí. Y ojalá nunca me aprese Eros (m'érōs héloi poté) / sin volverme hacia la intemperancia ni hacia Cipris (ouk eis tò môron oudé m'eis Kýprin trépōn $).{ }^{75}$

Haré dos aclaraciones: 1. La primera frase es independiente de lo que sigue. Una innovación es la idea de que Eros "apresa", "arrebata" (hairéō), a una persona; 2. el adjetivo môros es poco frecuente en griego. Su acepción principal es la de "necio", "estúpido", "loco": lo significativo es que, en varios pasajes euripideos como el presente, el término se aplica a la intemperancia sexual, lo que constituye una innovación.

7.5.2. Al mismo agón corresponderían los siguientes versos, quizá dirigidos por Polidectes ${ }^{76}$ a Dánae:

Y que el padre a los hijos les tolere con agrado / sus amores (synekphérein / érōtas), expulsando su orgullo, / y los hijos, al padre. Pues no son voluntarios / para los hombres los amores ni enfermedad aceptada (ouk authaíretoi / brotô̂s érōtes oud'hekousía nósos). / Que asunto infausto suele suceder / cuando alguien los destinos de los dioses quiere remediarlos. ${ }^{77}$

Mencionaré tres detalles: 1. La expresión synekphérein érōtas sólo aparece aquí; 2. de la pareja authaíretoi érōtes, "amores voluntarios", nada más he hallado un reflejo posterior en Menandro (Asp., 288, Sandbach); 3. la construcción hekousía nósos, "enfermedad aceptada", es otra innovación euripidea.

\subsection{Erecteo $^{78}$}

Erecteo, rey de Atenas, hace venir desde el palacio a su hijo adoptado ${ }^{79}$ para aconsejarle, en previsión de que él no pudiera volver de la batalla:

\footnotetext{
${ }^{74}$ Cuando Dánae y su hijito Perseo llegaron en su cofre a la isla de Sérifos, Dictis, hermano de Polidectes, los recogió y, luego, crió al pequeño.

${ }^{75}$ Fr. 331.1 (= 5 Jouan-van Looy, 2000). Estobeo (1, 9, 4a) conservó el fragmento.

76 Polidectes, rey de Sérifos, se enamoró de Dánae y quiso unirse con ella.

${ }^{77}$ Fr. 339.2.4 (= 7 Jouan-van Looy, 2000). Texto recogido por Estobeo $(4,26,16)$.

78 Se llevó a escena entre 423 y 416 a. C. Jouan-van Looy 2000 ofrecen 25 fragmentos. Para la reconstitución de la tragedia son imprescindibles los testimonios de Licurgo y Estobeo, además del P. Sorb. 2328, del s. III d. C. Entre los estudios más destacados sobre dicha obra, cf. Schwartz 1917, Schmitt 1921, Calder III 1969, Kamerbeek 1970 y 1991, van Looy 1970, Clairmont 1971, Treu 1976, Martínez Díez 1975 y 1976, Aigner 1982, Lacore 1983 y 1995-1996, O’Connor-Visser 1987.

${ }^{79}$ No hay acuerdo sobre si se trata de Ión, Juto o Cécrope. Los críticos se inclinan mayoritariamente por el primero.
} 
Sin gozarte en tu poder, hijo, / no persigas ${ }^{80}$ amores vergonzosos de tus conciudadanos (aischroùs érōtas dēmotôn diōkathền), / lo que atrae el hierro y la horca, ${ }^{81}$ / si uno a los hijos de pobres honrados avergüenza (chrēstôn penétōn èn tis aischýnēi tékna). ${ }^{82}$

Haré tres aclaraciones: 1. En "amores vergonzosos" entiéndase los que les producen vergüenza a quienes los reciben. En cuanto "a tus conciudadanos", tómese como genitivo objetivo, dependiente de "amores". Los estudiosos señalan que el abuso sexual contra jóvenes y mujeres adultas cometido por los tiranos incitaba a matarlos como venganza. 2. Para la noción de "perseguir" (diōkáthō, verbo innovador, muy raro en comparación con el usual diókō), advirtamos que puede tratarse de una imagen tomada de la caza, ligada aquí a la de perseguir a la persona deseada; 3. otra imagen novedosa es la del "pobre honrado".

\subsection{Hipólito velado 83}

En el episodio primero, Fedra y la nodriza dialogan. Una vez que aquélla confiesa su amor por Hipólito, ésta decide ir en busca del joven:

Tengo un maestro de audacia y osadía (tólmēs kaì thrásous didáskalon), / en imposibles muy rico (en tô̂s amēchánoisin euporótaton), / a Eros, el dios más invencible de todos (pántōn dysmachótaton theón). ${ }^{84}$

Mencionaré tres detalles: 1. Ser maestro de "audacia y osadía" es una idea innovadora; 2. otra nota conspicua sobre Eros es llamarlo "maestro".

${ }^{80} \mathrm{El}$ infinitivo con valor imperativo es muy raro en Eurípides, en quien pueden encontrarse otros ejemplos: $T r$., 422; Or., 624.

${ }^{81}$ Referencia velada al modo de defenderse del ofendido: o atacar con arma blanca o suicidarse ahorcándose. Eurípides menciona mucho el término "horca". Varios personajes, especialmente mujeres, recurren a eso para acabar con sus males: Hipp., 777 (Fedra se había ahorcado; y cf. 802), Andr., 816 (Hermíone lo había intentado varias veces), Hel., 200 (Leda se ahorcó por la deshonra de Helena), 299 (Helena no lo acepta para sí y lo tiene como inapropiado incluso para esclavos), $P$ h., 333 (Edipo lo intentó por haber maldecido a sus hijos); etc.

${ }^{82}$ Fr. 362.25 (= 19 Jouan-van Looy, 2000).

${ }^{83}$ Tanto en esta pieza como en la siguiente es central el llamado motivo de Putifar, ya señalado. Esta tragedia se habría llevado a la escena entre los años 455-429 a. C. En todo caso es anterior al Hipólito conservado (428 a. C.). Jouan-van Looy 2000 recogen 23 fragmentos, pero los dos últimos son inciertos. Para la reconstitución, entre otros testimonios, son imprescindibles Aristófanes, Estobeo y el PMich. 6222 A de los ss. II-III d. C. Recojo algunas aportaciones sobre dicha pieza de la que hay una extensa bibliografía: Kalkmann 1882, Kakridis 1928, Herter 1940 y 1942, Scheidweiler 1948, Friedrich 1953, Fauth 1958-1959, Yohannan 1968, Tschiedel 1969, Dingel 1970, Paratore 1972, Kiso 1973, Reckford 1974, Rocca 1976, Newton 1980, Jakob 1983, Mette 1983, Ley 1987, Craik 1987, Danek 1992, Luppe 1994, Gibert 1997.

${ }^{84}$ Fr. 430.3 (= 4 Jouan-van Looy, 2000). Transmitido por Estobeo (4, 20a, 25). 
Concretamente con esos dos términos sólo hay una secuencia posterior, en Anaxándrides (Fr. 62.1, Kassel-Austin). En cambio es muy importante en la posteridad la pareja Eros-"enseñar", que vimos en el apartado 7.1.1. 3. No he encontrado huellas ulteriores de la expresión "muy rico en imposibles"; tampoco de la relación de Eros con eúporos, "rico en recursos", "bien provisto". Sí he hallado su construcción con amếchanos, "sin remedio", "imposible de resolver". En lo tocante a Eros como dýsmachos, "imposible de vencer", "invencible", se trata de otra innovación euripidea.

\subsection{Estenebea ${ }^{85}$}

7.8.1. Belerofonte, en el prólogo, recuerda que Preto, soberano de Tirinto, le dio hospitalidad en el pasado y cómo la esposa de éste (sc. Estenebea) trataba de convencerlo con sus palabras y lo perseguía con astucia para que se uniera con ella en el lecho, apoyada en todo por la nodriza. Pero él no había admitido nunca tales proposiciones ni aceptó ultrajar un palacio enfermo, siendo huésped del mismo. Y sigue su explicación de este modo:

Por detestar un amor terrible (misôn érōta deinón) que destruye (phtheírei) a los mortales. / Que dobles son los amores (diplô̂...érōtes) nutridos en la tierra: / uno, siendo odiosísimo, lleva al Hades, / y, hacia la castidad y la virtud (eis tò sôphron ep'aretèn t'ágōn érōs) conduce el otro amor, / envidiado (zēlōtós) por los hombres, uno de los cuales ojalá sea yo. / Por tanto pienso morir incluso siendo casto (thaneîn ge sōphronôn). ${ }^{86}$

Haré siete observaciones: 1. eros como objeto directo de "odiar" aparece aquí por primera vez; 2 . el verbo phtheíro abarca entre sus valores el de "seducir", y, especialmente, "corromper", tanto en sentido físico como moral. El hecho de que Eros sea el sujeto de dicho verbo es una innovación euripidea. 3. La imagen de un eros dúplice es otra novedad; 4. respecto a tò sôphron y el sentido innovador que adquiere en Eurípides, ya nos ocupamos en el apartado 2.14; 5. la imagen de que Eros "conduce" (con distintos complementos: directos, indirectos o locales) es otra innovación euripidea, ya vista; 6. que Eros sea "envidiado" es otra aportación novedosa; 7. del uso especial que Eurípides hace de sōphronéo, no con el sentido de "ser sensato", "ser prudente", sino "ser casto", ya hablamos en 2.14.

${ }^{85}$ Su representación primera es de fecha incierta: 438-428 a. C. Jouan-van Looy 2002 recogen 12 fragmentos. Para la reconstitución son imprescindibles Aristófanes y sus escolios, Ateneo, Estobeo, Tzetzes, Juan Logotetes y el POxy. 2455. Acerca de la pieza, en general, cf. Papamichael 1983, Jouan 1989-1990, Silva 2016.

${ }^{86}$ Fr. 661.21.22.24 (= 1 Jouan-van Looy, 2002). El texto fue transmitido por Juan Logotetes, comentarista bizantino del s. XII (in Herm., 447, 14-33). 
7.8.2. Tras la párodo, en el curso del episodio primero, la nodriza explica la pasión concebida por su señora, y cómo se siente incapaz de darle ánimo:

$\mathrm{Al}$ poeta (poiètè̀n), pues, / Eros le enseña (Érōs didáskei), aunque ajeno (ámousos) a las Musas fuera antes. ${ }^{87}$

Señalo dos puntos: 1. Innovador es el pensamiento de que Eros enseña al poeta; 2. la idea del poeta "ajeno a las Musas" es novedosa, y el adjetivo ámousos, "ajeno a las Musas", es otra aportación léxica euripidea; el concepto es bastante usado en autores posteriores.

7.8.3. De labios de la nodriza, también en el episodio primero, procedería el verso y medio siguiente:

Tal agitación (alýei) tiene. Mas, reprendido Eros (nouthetoúmenos d'érōs), / acosa más (mâllon piézei) ${ }^{88}$

Mencionaré tres consideraciones: 1 . El verbo alýō, "estar agitado", "estar inquieto", se dice aquí de Estenebea, la cual debería sufrir alguna perturbación, próxima al delirio, quizá por sus remordimientos a causa de haber acusado injustamente a Belerofonte de intentar unirse amorosamente con ella; 2. en cuanto a la relación Eros-nouthetéo, "reprender", aquí en voz media, es otra innovación léxica euripidea; 3. sobre que Eros "acosa", innovación euripidea, hay raras muestras en la literatura posterior.

\subsection{Faetón ${ }^{89}$}

Un coro de doncellas entona un himeneo: primero, en honor de Afrodita, y, después, de un personaje no mencionado. ${ }^{90}$ Me ciño a la primera parte: ${ }^{91}$

${ }^{87}$ Fr. 663.2 (= 2 Jouan-van Looy, 2002). El verso y medio ha sido transmitido total o parcialmente por numerosas fuentes: entre ellas, Aristófanes ( $V$., 1074), Plutarco (en varios lugares: 196e, 405e, 622c, 762b), Elio Aristides (41, 11; 26, 3), Pseudo-Longino (39, 2). Además hay una alusión, con paráfrasis, en Platón (Smp., 196e).

${ }^{88}$ Fr. 665.1 (= 4 Jouan-van Looy, 2002). Los versos son citados, con alguna variante, por Aristófanes $(V ., 111$, parodia de los versos euripideos. Cf. también en ese mismo sentido el escolio correspondiente), Plutarco (71a), Galeno (5, 411, 7= 276, 16-17, De Lacy, Corpus Medicorum Graecorum. Corresponde asimismo a Crisipo, Fr. 475 von Arnim).

${ }^{89} \mathrm{La}$ fecha, incierta, de la primera representación suele establecerse entre 427 y 414 a. C. Jouan-van Looy 2002 recogen 12 fragmentos: los tres últimos resultan inciertos. Para la reconstitución han sido esenciales, entre otros, los testimonios de Estrabón, Pseudo-Longino, Diógenes Laercio, Estobeo y el POxy. 2455. Entre las contribuciones sobre dicha pieza sobresalen Lesky 1932, Scalvizzari 1934, Dain 1965, Reckford 1972, Contiades-Tsitsoni 1994.

${ }^{90}$ Unos piensan en Faetón, otros en Mérope (su padre putativo).

${ }^{91}$ Fr. 773.87-90, 2002. 
¡Himen, Himen, / a la celeste hija de Zeus cantamos, / la señora de los amores (tàn erôtōn pótnian), la que preside / las bodas de las doncellas, Afrodita! Señora, en tu honor estos cantos nupciales entono, / Cipris la más hermosa de las diosas, / y en el del recién uncido, / tu potro, ${ }^{92}$ al que en el éter escondes, / al nacido de tus bodas. ${ }^{93}$

De este fragmento tan importante (un breve himno. Nótese la repetición de Himen aunque el canto se dedica a Afrodita, muy relacionada con los Amores) $)^{94}$ me limitaré a un punto, a saber, la consideración de la diosa como "señora de los amores". El término pótnia (el femenino de pósis, "el señor", "el esposo", "el dueño de la casa") ${ }^{95}$ goza de una distribución especial desde Homero, en quien se atribuye de modo esencial a Hera, ${ }^{96}$ la señora de la mansión olímpica. Con respecto a Afrodita, la atribución de dicho calificativo la hallamos por primera vez en Píndaro $(P$., 4, 213, donde no consta el nombre de la diosa), y, a continuación, este fragmento euripideo, en que tenemos la presencia del teónimo por primera vez.

\subsection{Piezas inciertas (selecciono sólo un ejemplo):}

Abundantísima enseñanza de amable sabiduría (paídeuma d'Érōs sophías eratês) / Eros procura, / y esa divinidad (hoûtos daímōn) para relacionarse (prosomilê̂n) / con los mortales es la más grata de todas (pántōn hédistos). / Al ofrecer cierto placer sin pena (álypon térpsin tin') / lleva hacia la esperanza (eis elpíd'ágei). Y, con los no iniciados (tô̂s d'ateléstois) / en los sufrimientos causados por ése (tôn toûde pónōn), ojalá no me relacione yo, / y habite lejos de costumbres salvajes (agríōn trópōn). / El enamorarse (tò d'erân) aconsejo a los jóvenes (tô̂si néoisi) / que nunca lo rehúyan (pheúgein), / y que lo usen correctamente (orthôs) cuando llegue (élthēi). ${ }^{97}$

Realizaré varias anotaciones: 1 . No hay otros ejemplos de la estrecha relación Eros-paídeuma (sustantivo que apunta al "resultado de la educación",

92 En poesía es común llamar "potro/a" al hijo/a joven. La interpretación de los estudiosos se divide en este punto: unos opinan que se trata de Himen (para muchos, nacido de Afrodita y Dioniso), muerto en su noche de bodas; otros, que se habla de Eros.

${ }^{93} \mathrm{Fr} .781 .29$ (= 4 Jouan-van Looy, 2002).

${ }^{94} \mathrm{Cf}$. nuestros apartados 1.5, donde la diosa les ordena que tomen asiento a su lado, y 6 , lugar donde leemos que los Amores viven en Chipre, la isla de esa divinidad. Por otra parte, desde Píndaro (Fr. 122.4.5, Maehler) se considera a Afrodita "madre de los amores".

${ }^{95}$ Acúdase a Chantraine 1968, p. 931, quien se detiene en su origen a partir del indoeuropeo *poti- y alude a la teoría que postula su procedencia desde un antiguo *pot-, sin descartar la relación de una partícula *pet-, *pot- con un pronombre que señalaría la ipseidad.

${ }^{96}$ He aquí unos cuantos ejemplos: Hom., Il., 1, 551 y 568; 4, 2 y 50; 8, 198, 218 y 471; 13, $826 ; 14,155,197,222,263,300$ y $329 ; 15,34,49,83$; etc.

${ }^{97} \mathrm{Fr} .897 .1$ (= Jouan-van Looy, 2003). Conservado por Ateneo (13, 561a). Este texto relevante, en ritmo anapéstico, ha sido atribuido por unos a la Andrómeda, y, por otros, al Hipólito perdido, pero no hay acuerdo entre los estudiosos. 
"enseñanza"); 2. sí hemos visto la relación de eros con didáskō y didáskalos: cf. apartados 7.1.1 y 7.7; 3. Eros como divinidad (daímōn) aparece quizá por primera vez en un discutido texto de Sófocles (Fr. 770.1, Radt), y, después, en este fragmento incierto de Eurípides. Es Platón (Smp., 203a) quien asienta definitivamente esa consideración. 4. La idea del "placer sin pena", que no tiene continuadores en la literatura griega, la ofrece el trágico en otro lugar $(B a$., 423$)$, donde el Coro se refiere a cómo Dioniso ha permitido, tanto al rico como al pobre, disfrutar de un placer sin pena dado por el vino); 5. el adjetivo atélestos usado desde Homero con el sentido de "no terminado", lo hallamos ahora en nuestro trágico (el único de los tres que lo recoge) con otro valor: "no iniciado", entiéndase referido a los ritos mistéricos; 6. en la construcción tôn toûde pónōn tómese toûde como genitivo subjetivo, es decir, como el sujeto causante (sc. Eros) de esos sufrimientos; 7. la expresión "costumbres salvajes" alude posiblemente a quienes no están moderados por la iniciación amorosa; 8. el infinitivo erân lo encontramos, en primer lugar, en Píndaro, y, luego, en nuestro trágico, quien, al utilizarlo en diez ocasiones, muestra un claro interés por el vocablo.

\section{Conclusiones}

Partiendo de los datos de que disponemos (no olvidemos que conservamos más obras euripideas que de los otros dos trágicos juntos), puede afirmarse que Eurípides, heredero de una larga tradición literaria, aporta innovaciones importantes con respecto a éros. Señalo algunas y doy entre paréntesis el apartado donde las hemos visto:

1. Sobre la genealogía del dios ofrece un nuevo parentesco de Eros, presentándolo como hijo de Zeus (2.10-13).

2. El autor es innovador en lo referente a ciertos aspectos descriptivos de esta divinidad: Eros tiene alas de varios colores (2.17); es el más poderoso de todos los dioses y el más importante para los hombres (7.3); es peligroso y habita en la parte peor de nuestro corazón (7.1.2); es ocioso, ama los espejos y evita los esfuerzos (7.4). El trágico habla de dos clases de amor: uno lleva al Hades, el otro, hacia la castidad (7.8.1); asimismo, Eros puede conducir hacia la intemperancia y a Cipris (7.5.1).

3. También son innovadoras ciertas notas dramáticas de esta deidad: lanza con sus manos el dardo de Afrodita (2.10-13); junto a Cipris, ataca el corazón de dioses y hombres (2.17); tiende un arco doble (5.1); es el tirano de dioses y hombres (7.1.1); instila el deseo en los ojos (2.10-13); tiene la llave de la alcoba de Afrodita (2.10-13); es maestro de audacia y osadía (7.7); enseña al poeta (7.8.2); hechiza a quien asalta (2.17); golpea a la enamorada (1.1); destruye a los humanos (7.8.1); es enloquecer (7.2.1). 
Para concluir este estudio, recordemos que el tragediógrafo presenta a éros incluso en el plano divino, como la pasión de una diosa por un mortal (2.7). No obstante, prevalece la esfera humana, donde lo muestra con frecuencia como deseo sexual de una mujer por un hombre, tanto en la realidad $(1.1 ; 1.2 ; 2.1 ; 2.2 ; 2.3-4 ; 2.5 ; 2.8 ; 2.14 ; 2.15-16 ; 2.18)$ como referido a un sentimiento posible (4). Asimismo, alude a la pasión sexual de un hombre por una mujer $(3.1 ; 5.2-3)$. Por último, indica que todo varón es sabio para el amor (7.2.2).

\section{BIBLIOGRAFÍA}

\section{Fuente antigua: Eurípides}

De todas las piezas conservadas

EurIPIDIS Fabulae. Tomus I: Cyclops, Alcestis, Medea, Heraclidae, Hippolytus, Andromacha, Hecuba, ed. James Diggle, Oxford, Oxford University Press (Oxford Classical Texts), 1984.

EuriPIDIs Fabulae. Tomus II: Supplices, Electra, Hercules, Troades, Iphigenia in Tauris, Ion, ed. James Diggle, Oxford, Oxford University Press (Oxford Classical Texts), 1981.

EuriPIDIs Fabulae. Tomus III: Helena, Phoenissae, Orestes, Bacchae, Iphigenia Aulidensis, Rhesus, ed. James Diggle, Oxford, Oxford University Press (Oxford Classical Texts), 1994.

EuRIPIDIS Fabulae, III, ed. Gilbert Murray, Oxford, Clarendon Press (Oxford Classical Texts), 1909.

\section{Medea}

EurIPIDE, Medea, Ippolito, intr. e trad. Umberto Albini, note Maurizia Matteuzzi, Milano, Garzanti Libri, 1990.

EuriPIDEs, Medea, intr., ed., com. Denys L. Page, Oxford, Clarendon Press, 1967 (1938).

EurIPIDES, Medea, intr., ed., com., explic., vocab. Alistair Elliot, Oxford, Oxford University Press, 1969.

EuriPIDEs, Medea, intr., ed., com. Donald J. Mastronarde, Cambridge, Cambridge University Press, 2002.

\section{Hipólito}

EurIPIDE, Ippolito, intr., ed., com. Francesca Nenci, Milano, Signorelli, 2004.

EurIPIDES, Hippolytos, intr., ed., com. William Spencer Barrett, Oxford, Clarendon Press, 1964.

EurIPIDES, Hippolytos, intr., ed., trad., com. John Ferguson, Bristol, Bristol University Press, 1994.

EuRIPIDES, Hippolytos, intr., ed., trad., com. Michael Ros Halleran, Warminster, Aris \& Phillips, 1995.

\section{Troyanas}

EurIPIDE, Le Troiane, intr., ed., com. Angelo Taccone, Torino, Società Editrice Internazionale, 1942. 
EuRIPIDES, Troades, intr., ed., com. Kevin Hargreaves Lee, Basingstoke, Macmillan, 1976.

EurIPIDES, Trojan Women, intr., ed., trad., com. Shirley A. Barlow, Warminster, Aris \& Phillips, 1986.

\section{Helena}

EurIPIDES, Helen, intr., ed., com. Amy Marjorie Dale, Oxford, Clarendon Press, 1967.

EuriPIDES, Helen, intr., ed., com. William Allan, Cambridge, Cambridge University Press, 2008.

EuRIPIDES, Helena, intr., ed., com. Richard Kannicht, 1-2, Heidelberg, Winter, 1968.

\section{Ifigenia en Áulide}

EuRIPIDE, Iphigénie à Aulis, intr., ed., trad., com. François Jouan, Paris, Les Belles

Lettres, 1983.

EurípIDEs, Tragedias V. Heracles. Ifigenia en Áulide, intr., ed., trad., com. Esteban Calderón Dorda, Madrid, Consejo Superior de Investigaciones Científicas, 2002.

EuRIPIDIS Iphigenia in Aulis. Mit deutschem Commentar herausgegeben von Carl Georg Firnhaber, Leipzig, Han'sche Verlag-Buchhandlung, 1841.

\section{Bacantes}

EuRIPIDEs, Bacchae, intr., ed., com. Eric Robertson Dodds, Oxford, Clarendon Press, 1970.

EuRIPIDES, Bacchae, intr., ed., trad., com. Richard Seaford, Warminster, Aris \& Phillips, 2001.

\section{Fragmentos}

EurIPIDE, Tragédies. Tome VIII. Ire partie: Fragments. De Aigeus à Autolykos, texte établi et trad. François Jouan-Herman van Looy, Paris, Les Belles Lettres, 1998.

EurIPIDE, Tragédies. Tome VIII. 2e partie: Fragments de Bellérophon à Protésilas, texte établi et trad. François Jouan-Herman van Looy, Paris, Les Belles Lettres, 2000.

EurIPIDE, Tragédies. Tome VIII. 3e partie: Fragments. De Sthénébée à Chrysippos, texte établi et trad. François Jouan-Herman van Looy, Paris, Les Belles Lettres, 2002.

EuRIPIDE, Tragédies. Tome VIII. 4e partie: Fragments de drames non identifiés, texte établi et trad. François Jouan-Herman van Looy, Paris, Les Belles Lettres, 2003.

Tragicorum Graecorum Fragmenta, ed. secunda Augustus Nauck, Leipzig, Teubner, 1889.

Tragicorum Graecorum fragmenta. Vol. V, Euripides, ed. Richard Kannicht, Göttingen, Vandenhoeck \& Rupprecht, 2004, 2 vols.

\section{Fuentes modernas}

Adrados, Francisco R., "El amor en Eurípides", en Manuel Fernández Galiano, José S. Lasso de la Vega y Francisco Rodríguez Adrados, El descubrimiento del amor en Grecia, Madrid, Universidad de Madrid, 1959, pp. 177-200. 
Adrados, Francisco R., "Las tragedias eróticas de Eurípides", Revista de Occidente, 107, 1990, pp. 5-32.

Aigner, Heribert, Der Selbstmord im Mythos. Betrachtungen über die Einstellung der Griechen zum Phänomen Suizid von der homerischen Zeit bis in das ausgehende 5. Jahrhundert v. Chr., Graz, Institut für Alte Geschichte und Altertumskunde, 1982.

AndERSOn, William S., "Euripides' Auge und Menander's Epitrepontes", Greek, Roman and Byzantine Studies, 23, 1982, pp. 165-177.

AssaËL, Jacqueline, "Euripide et la magie des miroirs", Revue des Études Grecques, 105, 1992, pp. 561-571.

Athanasopoulou, Eleftheria N., The motiv of love in the Helen and the Alcestis of Euripides, doctoral dissertation, Johannesburg, University of Johannesburg, 2008.

BITTRICH, Ursula, Aphrodite und Eros in der antiken Tragödie. Mit Ausblicken auf motivgeschichtlich verwandte Dichtungen, Berlin-New York, Walter de Gruyter, 2005.

Bremer, Jan Maarten, “The meadow of love and two passages in Euripides' Hippolytus", Mnemosyne, 28, 1975, pp. 268-280.

BrILl, Sara, “Aphrodite's Wrath: Eros in Euripides's Hippolytus”, Symposium, 11.2, 2007, pp. 275-295.

BrIZI, Giuseppe, "Il mito di Telefo nei tragici greci", Atene e Roma, 8, 1927, pp. 95-145.

Brulé, Pierre, "Héraclès et Augé. À propos d'origines rituelles du mythe”, en Colette Jourdain-Annequin-Corinne Bonnet (eds.), Héraclès. Les femmes et le féminin, Bruxelles, Institut Historique Belge de Rome-Turnhout, 1996, pp. 35-49.

CAlder III, William M., "The Date of Euripides'Erechtheus", Greek, Roman and Byzantine Studies, 10, 1969, pp. 147-156.

Chantraine, Pierre, Dictionnaire étymologique de la langue grecque, Paris, Klincksieck, 1968.

Clairmont, Christoph W., "Euripides'Erechtheus and the Erechtheion", Greek, Roman and Byzantine Studies, 12, 1971, pp. 485-495.

Conacher, Desmond J., Euripidean drama. Myth, theme and structure, Toronto, University of Toronto Press, 1967.

Contiades-Tsitsoni, Eleni, "Euripides. Pha. 227-144, Tro. 308-341, Iph. Aul. 10361079”, Zeitschrift für Papyrologie und Epigraphik, 102, 1994, pp. 52-60.

Cosmopoulos, Michael B., Bronze age Eleusis and the origins of the Eleusinian mysteries, Cambridge, Cambridge University Press, 2015.

Craik, Elisabeth, "Euripides'first Hippolytus", Mnemosyne, 40/4, 1987, pp. 137139.

Cyrino, Monica S., "Of Love and Bondage in Euripides' Hippolytus", in Mark Masterson-Nancy Sorkin Rabinowitz-James Robson (eds.), Sex in Antiquity. Exploring Gender and Sexuality in the Ancient World, London, Routledge, 2015, pp. 231-244.

Dain, Alphonse, "Reconstitution d'une partie du Phaéthon d'Euripide", Revue des Études Grecques, 78, 1965, p. xxvi. 
DANeK, George, "Zur Prologrede der Aphrodite im Hippolytus des Euripides", Wiener Studien, 105, 1992, pp. 19-37.

Diccionario de la Lengua española, Madrid, Real Academia Española, 2014.

Dingel, Joachim, "Hippólytos xiphulkós. Zu Seneca's Phaedra und dem ersten Hippolytus des Euripides", Hermes, 98, 1970, pp. 44-56.

FAuTH, Wolfgang, Hippolytos und Phaidra. Bemerkungen zum religiösen Hintergrund eines tragischen Konflikts, I und II, Mainz, Akademie der Wissenschaften und der Literatur (Abhandlungen der Geistes und Sozialwissenschaftlichen Klasse, 8-9), 1958-1959.

FrIEDRICH, Wolf-Hartmut, Euripides und Diphilos, München, Beck, 1953.

Furley, William D.-Jan Maarten Bremer, Greek Hymns. Selected Cult Songs from the Archaic to the Hellenistic Period, I-II, Tübingen, Mohr Siebeck. GWCoronet Books, 2001.

Gentili, Bruno, "Il 'letto insaziato' di Medea e il tema dell'adikía a livello amoroso nei lirici (Saffo, Teognide) e nella Medea di Euripide", Studi Classici e Orientali, 21, 1972, pp. 60-72.

Ghiron-Bistagne, Paulette, "Antigone ou l'amour imposible", en Albert MachinLucien Pernée (eds.), Sophocle. Le texte, les personnages. Actes du Colloque international d'Aix-en-Provence 1992, Aix-en-Provence, Publications de l’Université de Provence, 1993, pp. 255-263.

Gibert, John C., "Euripides'Hippolytus-plays: which came first", The Classical Quarterly, 47/1, 1997, pp. 85-97.

Gibert, John C., "Falling in Love with Euripides (Andromeda)", Illinois Classical Studies, 24-25, 1999-2000, pp. 75-91.

Goldman, Shalom, The Wiles of Women/The Wiles of Men: Joseph and Potiphar's Wife in Ancient Near Eastern, Jewish and Islamic Folktales, Albany, State University of New York Press, 2005.

Hermann, Gottfried J., De interpretationibus Euripideae Iphigeniae in Aulide, tesis, Leipzig, 1846-1847.

Herter, Hans, "Theseus und Hippolytus", Rheinisches Museum für Philologie, 89, 1940, pp. 273-292.

Herter, Hans, "Theseus und Hippolytus", Rheinisches Museum für Philologie, 91, 1942, pp. 228-237.

Hualde Pascual, Pilar, "Metáforas del amor en la poesía de la Grecia antigua (II): De la tragedia ática a la poesía helenística”, Cuadernos de Filología Clásica. Estudios Griegos e Indoeuropeos, 28, 2018, pp. 41-81.

Huddilston, John Homer, "An archaeological Study of the Antigone of Euripides", American Journal of Archaeology, 2/3, 1899, pp. 183-201.

Huys, Marc, "Euripides, Auge, Fr. 265, 272, 278, $864 \mathrm{~N}^{2}$ and the Role of Herakles in the Play", Sacris Erudiri, 31, 1989-1990, pp. 169-186.

JАKоB, Daniel J., "Euripides Hippolytos kalyptomenos fr. $443 \mathrm{~N}^{2}$. A reconsideration", Wiener Studien, 96, 1983, pp. 23-26.

JouAn, François, "Femmes ardentes et chastes héros chez Euripide", Sacris Erudiri, 31, 1989-1990, pp. 187-208.

KAKrIDIs, Johannes Theophanes, "Der Fluch des Theseus im Hippolytus", Rheinisches Museum für Philologie, 77, 1928, pp. 21-33. 
Kalkmann, August, De Hippolytis euripideis quaestiones novae, Bonn, E. Strauss, 1882.

Kamerbeek, Jan Coenraad, "Remarques sur les fragments de l'Érechtée d'Euripide", Mnemosyne, 23/2, 1970, pp. 113-126.

KAMERBeek, Jan Coenraad, "En relisant les fragments de l'Érechtée d'Euripide", in Heinz Hofmann-Annette Harder (eds.), Fragmenta Dramatica. Beiträge zur Interpretation der griechischen Tragikerfragmente und ihrer Wirkungsgeschichte, Götingen, Vandenhoeck, 1991, pp. 111-116.

Kannicht, Richard, "Euripides in P. Hibeh 2179”, Zeitschrift für Papyrologie und Epigraphik, 21, 1976, pp. 127-133.

Kannicht, Richard, "Antigone Bacchans. Eine Problemanzeige zur Antigone des Euripides”, en Heide Froning et alii (eds.), Kotinos. Festschrift für Erika Simon, Mainz, Philipp von Zabern, 1992, pp. 252-255.

Kannicht, Richard, "Die Hypothesis zu Euripides'Danae", Zeitschrift für Papyrologie und Epigraphik, 90, 1992, pp. 33-34.

KIso, Akiko, "Sophocles'Phaedra and the Phaedra of the first Hippolytus", Bulletin of the Institute of Classical Studies, 20, 1973, pp. 22-36.

Koenen, Ludwig, "Eine Hypothesis zur Auge des Euripides und tegeatische Plynterien (PCol. inv.264)", Zeitschrift für Papyrologie und Epigraphik, 4, 1969, pp. 7-18.

KöRTE, Alfred, "Zum griechischen Drama. Ein übersehenes Fragment des Euripides?", Hermes, 67, 1932, pp. 367-368.

Kugel, James L., In Potiphar's House: The Interpretive Life of Biblical Texts, Cambridge, Harvard University Press, 1990.

Lacore, Michelle, "Euripide et le culte de Poséidon-Érechthée", Revue des Études Anciennes, 85, 1983, pp. 215-234.

Lacore, Michelle, "Mort et divinisation des filles du roi d'Athènes dans l'Érechtée d'Euripide", Kentron, 11/2-12/1, 1995-1996, pp. 89-107.

Lauriola, Rosanna-Kyriakos N. Demetriou (eds.), Brill's Companion to the Reception of Euripides, New York-Leiden, Brill, 2015.

Lesky, Albin, "Zum Phaethon des Euripides”, Wiener Studien, 50, 1932, pp. 1-25.

LeY, Graham K. H., "Placing Hippolytus Kalyptomenos", Eranos, 85, 1987, pp. 66-67.

Looy, Herman van, "L'Érechtée d'Euripide", en Hommages à Marie Delcourt, Bruxelles, Latomus, 1970, pp. 15-22.

López Férez, Juan Antonio, "Sóphrōn y môros en Eurípides. Sobre norma y uso en el léxico”, Epos, 3, 1987, pp. 207-220.

López FÉrez, Juan Antonio, "Eros en Eurípides. Función dramática”, en Actas VII Congreso español de estudios clásicos (Madrid, 20-24/04/1987), II, Madrid, Editorial Universidad Complutense, 1989, pp. 245-251.

López FÉrez, Juan Antonio, "Nueva lectura de sophía-sophós en la Medea de Eurípides", Eikasmós, 13, 2002, pp. 41-61.

López Férez, Juan Antonio, Mitos en las obras conservadas de Eurípides, Madrid, Ediciones Clásicas, 2014.

LuCAs, Hans, "Der Prolog der Antigone des Euripides", Hermes, 72, 1937, pp. 239240. 
LupPe, Wolfgang, “Auge Fr. 270”, Studi Italiani di Filologia Classica, 53, 1981, p. 275.

LuPPE, Wolfgang, "Die Hypothesis zu Euripides'Auge", Archiv für Papyrusforschung und verwandte Gebiete, 29, 1983, pp. 19-24.

LuPPE, Wolfgang, "Pannychis kaì choreía", Zeitschrift für Papyrologie und Epigraphik, 64, 1986, p. 50.

LuPPE, Wolfgang, "Nochmals zur Zuordnung des Tragiker-Fragments POxy. 3317", Zeitschrift für Papyrologie und Epigraphik, 77, 1989, pp. 13-17.

LupPE, Wolfgang, "Die Hypothesis zu Euripides'Danae”, Zeitschrift für Papyrologie und Epigraphik, 87, 1991, pp. 1-7.

LuPPE, Wolfgang, "Nochmals zur Danae Hypothesis", Zeitschrift für Papyrologie und Epigraphik, 95, 1993a, pp. 65-69.

LupPe, Wolfgang, "Die beiden erotes im Bellerophontes-Prolog der Stheneboia des Euripides", Philologus, 137, 1993b, pp. 139-142.

LupPE, Wolfgang, "Die Hypothesis zum ersten Hippolytus (PMich. inv. 6222 a)", Zeitschrift für Papyrologie und Epigraphik, 102, 1994, pp. 23-39.

Márquez Guerrero, Miguel Ángel, "La metáfora 'el amor es una enfermedad' en el Hipólito de Eurípides”, en Esteban Torre (coord.), Actas del IV Simposio Interdisciplinar de Medicina y Literatura, Sevilla, Real Colegio Oficial de Médicos, 2004, pp. 43-63.

Martínez, Marcos, "Los himnos a Eros en la literatura griega", en Luis Gil-Marcelo Martínez Pastor-Rosa Ma Aguilar (eds.), Corolla Complutensis in memoriam J. S. Lasso de la Vega contexta, Madrid, Universidad Complutense, 1998, pp. 187-197.

Martínez Bermejo, María Llanos, La recepción de la tragedia fragmentaria de Eurípides. De Platón a Diodoro Sículo, tesis doctoral, Salamanca, Universidad de Salamanca, 2017.

Martínez Díez, Alfonso, "Reconstrucción del Erecteo de Eurípides", Emerita, 43/1, 1975, pp. 207-239.

Martínez DíEz, Alfonso, "Reconstrucción del Erecteo de Eurípides", Emerita, 44/1, 1976, pp. 1-22.

Mastronarde, Donald J., The art of Euripides: dramatic technique and social context, Cambridge, Cambridge University Press, 2010.

McClure, Laura (ed.), A companion to Euripides, Malden-Oxford, Wiley-Blackwell, 2017.

Mesk, Josef, "Die Antigone des Euripides", Wiener Studien, 49, 1931, pp. 1-11.

Mette, Hans Joachim, "Perithoos-Theseus-Herakles bie Euripides", Zeitschrift für Papyrologie und Epigraphik, 50, 1983, pp. 13-19.

Montanari, Franco, "Eros venerato ed Eros non venerato (Eur., Hipp. 525-544)", Annali della Scuola Normale Superiore di Pisa, 3, 1973, pp. 43-47.

Moorton, Richard, "Euripides'Andromeda in Aristophanes'Frogs", The American Journal of Philology, 108/3, 1987, pp. 434-436.

Morelli, Giuseppe, "Il modelo greco della Danae di Nevio", in Giulio Puccioni (ed.), Poesia latina in frammenti. Miscellanea Filologica, Genova, Università di Genova-Facoltà di Lettere. Istituto di Filologia Classica e Medievale, 1974, pp. 85-101. 
Morwood, James, The plays of Euripides, London, Bristol Classical Press, 2002.

Müller, Edwin, "Die Andromeda des Euripides", Philologus, 66, 1907, pp. 48-66.

MüLLER, Heinz Martin, Erotische Motive in der griechischen Dichtung bis auf Euripides, Hamburg, Buske, 1980.

Mureddu, Patrizia, "Un caso singolare di teatro nel teatro: la scena di Eco nelle Tesmoforiazuse", Annali della Facolta di Lettere e Filosofia dell' Università de Cagliari, 43/6, 1987, pp. 15-22.

Newton, Rick M., "Euripides'Hippolytus Kalyptomenos fr. 443 N2", Hermes, 108, 1980, pp. 492-495.

O'Connor-Visser, Elly A. M. E., Aspects of human Sacrifice in the Tragedies of Euripides, Amsterdam, B. R. Grüner, 1987.

Paduano, Guido, "Représentation et interdiction de l'amour chez Euripide", Pallas. Revue d' Études Antiques. Dramaturgie et Actualité du Théatre Antique, 38, 1992, pp. 259-265.

Papamichael, Emmanuel M., "Bellerophon and Stheneboea (or Anteia)", Dodone, 12, 1983, pp. 45-74.

Paratore, Ettore, "Lo Hippólytos kalyptómenos di Euripide e la Phaedra di Seneca. Discorso ai sordi", in Studi classici in onore di Q. Cataudella, I, Catania, Università Catania-Facoltà di Lettere, 1972, pp. 303-346.

Paton, James M., "The Antigone of Euripides", Harvard Studies in Classical Philology, 12, 1901, pp. 267-276.

Philips Jr., Kyle M., "Perseus and Andromeda", American Journal of Archaeology, 72, 1968, pp. 1-23.

Pucci, Pietro, "Eros in Euripides's Poetics: Sex as the Cause of the Trojan War", in Euripides' Revolution under Cover: An Essay, Ithaca-London, Cornell University Press, 2016, pp. 34-41.

RADERMACHER, Ludwig, "Danae und der goldene Regen”, Archiv für Religionswissenschaft, 25, 1927, pp. 216-218.

Rau, Peter, Paratragodia. Untersuchung einer komischen Form des Aristophanes, München, Beck, 1967.

RECKFORD, Kenneth J., "Phaethon, Hippolytus and Aphrodite", Transactions and Proceedings of the American Philological Association, 103, 1972, pp. 405-432.

RECKFORD, Kenneth J., "Phaedra und Pasiphae: the Pull backward", Transactions and Proceedings of the American Philological Association, 104, 1974, pp. 307328.

ReIn, Eduardus, "De Danaa euripidea", en Commentationes philologicae in honorem Professoris Emeriti I. A. Heikel, Helsinki, Suomal. kirjall. Seura, 1926, pp. 109-129.

RoccA, Rosanna, "Eliodoro e i due Ippoliti euripidei", Materiali e Contributi per la Storia della Narrativa Greco-Latina, 1, 1976, pp. 25-31.

SAnDERs, Ed, "Sexual Jealousy and Erôs in Euripides' Medea", in Ed Sanders, Chiara Thumiger, Christopher Carey and Nick Lowe (eds.), Erôs in Ancient Greece, Oxford-New York, Oxford University Press, 2013, pp. 41-58.

Scalvizzari, Maria Fiorenza, Il mito nel Phaéthon di Euripide, Napoli, Stab. tip. ed., 1934. 
SCHEIDWEILER, Felix, "Zu den beiden Hippolytosdramen des Euripides", Würzburger Jahrbücher für die Altertumswissenschaft, 3/2, 1948, pp. 232-240.

Schmiтt, Johanna, Freiwillige Opfertod bei Euripides: ein Beitrag zu seiner dramatischen Technik, Giessen, A. Töpelmann, 1921.

Schwartz, Maximilian August, Erechtheus et Theseus apud Euripidem et Atthidographos, tesis, Leiden, C. van Doesburgh, 1917.

SCODEl, Ruth, "POxy. 3317. Euripides'Antigone", Zeitschrift für Papyrologie und Epigraphik, 46, 1982, pp. 37-42.

Sealy, William Leigh, Mind and eros in four plays of Euripides: a dramaturgical approach, Stanford, Stanford University, 1980.

Silva, Maria F., "Historias de amor y adulterio. Las Fedras y las Estenebeas de Eurípides", Revista de Estudios Clásicos, 43, 2016, pp. 175-210.

Sissa, Giulia "Medea's Erotic Jealousy", in Shane Butler (ed.), Deep classics. Rethinking classical reception, London, Bloomsbury Academic, 2016, pp. 203220.

Tessier, Andrea, "Ricognizioni al testo dell'Andromeda euripidea", Atti e Memoriae dell'Accademia Patavina di Scienze, 86/3, 1973-1974, pp. 139-154.

Treu, Max, "Der euripideische Erechtheus als Zeugnis seiner Zeit", Chiron, 1, 1976, pp. 115-131.

Tschiedel, Hans Jürgen, Phaedra und Hippolytus. Variationen eines tragischen Konfliktes, Bonn, Habelt, 1969.

Walton, John Michael, Euripides: our Contemporary, Berkeley-Los Angeles-London, University of California Press, 2009.

Webster, Thomas Bertram Lonsdale, "The Andromeda of Euripides", Bulletin of the Institute of Classical Studies, 12, 1965, pp. 29-33.

WiCKKISER, Bronwen L., “Cupid's Arrows”, Mnemosyne, 71/1, 2018, pp. 100-124.

Wünsch, Richard, "Der pseudoeuripideische Anfang der Danae", Rheinisches Museum für Philologie, 51, 1896, pp. 138-152.

Xanthakis-Karamanos, Georgia, "POxy. 3317. Euripides'Antigone?", Bulletin of the Institute of Classical Studies, 33, 1987, pp. 107-111.

Yohannan, John D., Joseph and Potiphar's Wife in World Literature: an Anthology of the Story of the chaste Youth and the lustful Stepmother, New York, New Directions Books, 1968.

Zeitlin, Froma, "The Power of Aphrodite: Eros and the Boundaries of the Self in Hippolytus", in Froma Zeitlin, Playing the Other. Gender and Society in Classical Greek Literature, Chicago, University of Chicago Press, 1996, pp. 219-284.

ZIELINSKI, Tadeusz, "De Auge euripidea”, Eos, 30, 1927, pp. 33-56, 416.

$$
* * *
$$

Juan Antonio López Férez es doctor en Filosofía y Letras por la Universidad Complutense, Madrid, y catedrático emérito en Filología Griega por la Universidad Nacional de Educación a Distancia, España. Sus áreas de interés son Eurípides, los textos médicos griegos y la presencia de los mitos y la tradición clásica en la literatura española. Es investigador principal en cinco proyectos financiados por el Ministerio de Educación y Ciencia. Dirige la serie Estudios de filología griega, 
de Ediciones Clásicas, Madrid, y es codirector de la Colección de autores griegos, Ediciones Clásicas. Ha publicado más de 230 trabajos, muchos de ellos en revistas científicas. Sobresalen 21 libros, ya como autor, ya como editor, los más recientes son: Mitos en las obras conservadas de Eurípides. Guía para la lectura del trágico, Madrid, Ediciones Clásicas, 2014; Teorías de Galeno sobre el semen femenino, México, Universidad Nacional Autónoma de México, 2015; y Galeno. Preparación y constitución de textos críticos, entrega y publicación de obras propias o ajenas, Madrid, Ediciones Clásicas, 2018. 